\title{
Peripheral Tumor Necrosis Factor-Alpha (TNF- $\alpha$ ) Modulates Amyloid Pathology by Regulating Blood-Derived Immune Cells and Glial Response in the Brain of AD/TNF Transgenic Mice
}

\author{
Evi Paouri, Ourania Tzara, Georgia-Ioanna Kartalou, $\mathbb{D S}^{-}$Sofia Zenelak, and Spiros Georgopoulos \\ Laboratory of Cellular Neurobiology, Center of Basic Research, Biomedical Research Foundation, Academy of Athens, 11527, Athens, Greece
}

Increasing evidence has suggested that systemic inflammation along with local brain inflammation can play a significant role in Alzheimer's disease $(\mathrm{AD})$ pathogenesis. Identifying key molecules that regulate the crosstalk between the immune and the CNS can provide potential therapeutic targets. TNF- $\alpha$ is a proinflammatory cytokine implicated in the pathogenesis of systemic inflammatory and neurodegenerative diseases, such as rheumatoid arthritis (RA) and AD. Recent studies have reported that anti-TNF- $\alpha$ therapy or RA itself can modulate AD pathology, although the underlying mechanism is unclear. To investigate the role of peripheral TNF- $\alpha$ as a mediator of RA in the pathogenesis of $\mathrm{AD}$, we generated double-transgenic $5 \mathrm{XFAD} / \mathrm{Tg} 197 \mathrm{AD} / \mathrm{TNF}$ mice that develop amyloid deposits and inflammatory arthritis induced by human TNF- $\alpha$ (huTNF- $\alpha$ ) expression. We found that 5XFAD/Tg197 mice display decreased amyloid deposition, compromised neuronal integrity, and robust brain inflammation characterized by extensive gliosis and elevated blood-derived immune cell populations, including phagocytic macrophages and microglia. To evaluate the contribution of peripheral huTNF- $\alpha$ in the observed brain phenotype, we treated 5XFAD/Tg197 mice systemically with infliximab, an anti-huTNF- $\alpha$ antibody that does not penetrate the blood- brain barrier and prevents arthritis. Peripheral inhibition of huTNF- $\alpha$ increases amyloid deposition, rescues neuronal impairment, and suppresses gliosis and recruitment of blood-derived immune cells, without affecting brain huTNF- $\alpha$ levels. Our data report, for the first time, a distinctive role for peripheral TNF- $\alpha$ in the modulation of the amyloid phenotype in mice by regulating blood-derived and local brain inflammatory cell populations involved in $\beta$-amyloid clearance.

Key words: Alzheimer's disease; arthritis; blood-derived monocytes/macrophages; infliximab; microglia; peripheral TNF- $\alpha$

Significance Statement

Mounting evidence supports the active involvement of systemic inflammation, in addition to local brain inflammation, in Alzheimer's disease (AD) progression. TNF- $\alpha$ is a pluripotent cytokine that has been independently involved in the pathogenesis of systemic inflammatory rheumatoid arthritis (RA) and AD. Here we first demonstrate that manipulation of peripheral TNF- $\alpha$ in the context of arthritis modulates the amyloid phenotype by regulating immune cell trafficking in the mouse brain. Our study suggests that additionally to its local actions in the AD brain, TNF- $\alpha$ can also indirectly modulate amyloid pathology as a regulator of peripheral inflammation. Our findings may have significant implications in the treatment of RA patients with anti-TNF- $\alpha$ drugs and in the potential use of TNF-targeted therapies for AD.

\section{Introduction}

Alzheimer's disease (AD) is a progressive neurodegenerative disease characterized by severe memory loss and cognitive impair-

Received Aug. 2, 2016; revised March 20, 2017; accepted April 4, 2017.

Author contributions: S.G. designed research; E.P., O.T., G.-I.K., and S.Z. performed research; E.P. and S.G. analyzed data; E.P. and S.G. wrote the paper.

This work has been supported in part by the European Union (European Social Fund) and Greek national funds through the Operational Program "Education and Lifelong Learning" of the National Strategic Reference Framework-Research Funding Program: THALIS-UOA-Study of neurodegeneration mechanisms in Alzheimer's disease. We thank Dr. George Kollias (Biomedical Sciences Research Center "Alexander Fleming") for providing Tg197 transgenic mice and Dr. Marietta Armaka (Biomedical Sciences Research Center "Alexander Fleming") for providing advice for their treatment and maintenance; Dr. Stamatis Pagkakis and Dr. Eleni Rigana (Biomedical Research ment (Selkoe et al., 2012). Although $\beta$-amyloid (A $\beta$ ) aggregation is traditionally accepted to be the primary initiator of the disease, mounting evidence supports the active involvement of neuroinflammation (Heneka et al., 2015; Heppner et al., 2015). Mi-

Foundation, Academy of Athens) for assistance with confocal imaging; Dr. Ben Barres (Stanford University School of Medicine) for kindly providing the anti-TMEM119 antibody; and Dr. Mariko Bennett and Dr. Chris Bennett (Stanford University School of Medicine) for useful comments on our TMEM119 results.

The authors declare no competing financial interests.

Correspondence should be addressed to Dr. Spiros Georgopoulos, 4 Soranou Ephessiou St., 11527, Athens, Greece. E-mail: sgeorgopoulos@bioacademy.gr.

DOI:10.1523/JNEUROSCI.2484-16.2017

Copyright $\odot 2017$ the authors $\quad 0270-6474 / 17 / 375155-17 \$ 15.00 / 0$ 
croglia, the brain-resident immune cells, have been shown to accumulate around amyloid plaques and contribute to $\mathrm{A} \beta$ clearance (Cameron and Landreth, 2010; Lee and Landreth, 2010). Experimental data suggest that other mononuclear phagocytes, such as perivascular macrophages and peripheral monocytes, are also involved in $\mathrm{A} \beta$ removal (Simard et al., 2006; Hawkes and McLaurin, 2009). Recent work has suggested that systemic inflammation also affects the $\mathrm{AD}$ pathogenic process. Acute systemic inflammation caused by bacterial infection exacerbates AD pathology (O'Banion, 2014), whereas chronic systemic inflammation occurring in autoimmune diseases such as rheumatoid arthritis (RA) has also been reported to modify the amyloid phenotype of AD mice (Kyrkanides et al., 2011; Park et al., 2011).

Elevated production of proinflammatory molecules, such as TNF- $\alpha$, IL- $1 \beta$, and IL- 6 , has been implicated in AD process (Wyss-Coray and Rogers, 2012). TNF- $\alpha$ is a proinflammatory cytokine involved in the pathogenesis of chronic autoimmune diseases, such as RA, psoriasis, and Crohn's disease (Van Deventer, 1997; Choy and Panayi, 2001; Feldmann, 2002; Schottelius et al., 2004). The central role of TNF- $\alpha$ in these diseases has led to the development of anti-TNF- $\alpha$ therapeutics (Taylor and Feldmann, 2009; Blandizzi et al., 2014). Epidemiological studies have demonstrated that the relative $\mathrm{AD}$ risk is significantly reduced in RA patients receiving nonsteroidal anti-inflammatory drugs (McGeer et al., 1996; Etminan et al., 2003) or anti-TNF- $\alpha$ agents (Chou et al., 2016), suggesting that lowering inflammatory response is beneficial for AD. Moreover, case studies have reported that treatment of AD patients with the anti-TNF- $\alpha$ agents infliximab or etanercept resulted in rapid cognitive improvement (Tobinick and Gross, 2008; Tobinick, 2009; Shi et al., 2011a). TNF- $\alpha$ is increased in the serum and CSF of AD patients and has been detected in colocalization with amyloid plaques (Fillit et al., 1991; Dickson, 1997; Janelsins et al., 2005; Galimberti et al., 2008; Montgomery and Bowers, 2012). Elevated TNF- $\alpha$ levels have been also implicated in neurotoxicity (Perini et al., 2002; Takeuchi et al., 2006) and reflect disease severity (Paganelli et al., 2002), further supporting that TNF- $\alpha$ contributes to AD pathogenesis. Genetic ablation of TNF receptor-1 or administration of TNF- $\alpha$ inhibitors in $\mathrm{AD}$ mice results in attenuation of the amyloid phenotype (He et al., 2007; McAlpine et al., 2009; Shi et al., 2011b; Tweedie et al., 2012; Gabbita et al., 2015), suggesting that inhibition of TNF- $\alpha$ signaling confers a protective effect against A $\beta$ related pathology. Meanwhile, transient hippocampal TNF- $\alpha$ expression decreased amyloid deposition (Chakrabarty et al., 2011), whereas chronic neuronal TNF- $\alpha$ expression exacerbated $\mathrm{A} \beta$ pathology (Janelsins et al., 2008) in the mouse AD brain, suggesting that TNF- $\alpha$ may exert either a beneficial or detrimental role in AD probably depending on differences in the spatiotemporal TNF- $\alpha$ expression pattern. Although these studies point toward a significant role for TNF- $\alpha$ in AD pathogenesis, it is not clear whether inhibiting or enhancing TNF- $\alpha$ signaling could serve as a therapeutic approach for $\mathrm{AD}$.

Considering that both RA and TNF- $\alpha$ have been implicated in the pathogenesis of $\mathrm{AD}$, we investigated the role of TNF- $\alpha$ as a mediator of systemic inflammatory arthritis in the progression of amyloid pathology. We generated double-transgenic 5XFAD/Tg197 AD/TNF mice that combine amyloid pathology (Oakley et al., 2006) and human TNF- $\alpha$ (huTNF- $\alpha$ ) expression resulting in inflammatory polyarthritis (Keffer et al., 1991). As huTNF- $\alpha$ is expressed both peripherally and centrally, we treated 5XFAD/Tg197 mice systemically with infliximab anti-huTNF- $\alpha$ antibody, which inhibits the arthritic phenotype (Shealy et al., 2002), to assess the impact of blocking only peripheral huTNF- $\alpha$ on the amyloid phenotype. Analysis of 5XFAD/Tg197-treated and un- treated mice revealed that peripheral huTNF- $\alpha$ can modulate the amyloid pathology by regulating blood-derived immune cell trafficking into the brain.

\section{Materials and Methods}

Animals. 5XFAD mice were purchased from The Jackson Laboratory and maintained on a C57BL/6J genetic background. 5XFAD is a wellestablished AD mouse model that harbors 3 amyloid precursor protein (APP) mutations and 2 presenilin 1 (PS1) mutations linked to familial AD (FAD) (Oakley et al., 2006). Tg197 transgenic mice were kindly provided by Dr. G. Kollias (Biomedical Sciences Research Center "Alexander Fleming") and maintained on a C57BL/6J genetic background. Tg197 mice, carrying a $3^{\prime}$-modified human TNF-globin transgene, show deregulated patterns of huTNF- $\alpha$ gene expression and develop chronic inflammatory polyarthritis (Keffer et al., 1991). Both 5XFAD and Tg197 transgenic lines were maintained as hemizygotes. For the purposes of the present study, we crossed 5XFAD mice with Tg197 mice to obtain 5XFAD/ Tg197 AD/TNF double-transgenic mice along with 5XFAD, Tg197, and wild-type (C57BL/6) littermates. Only female mice were used in the analysis, as 5XFAD females develop the amyloid phenotype 2 months earlier than 5XFAD males (Oakley et al., 2006; Sesele et al., 2013). Mouse genotyping was performed with PCR. Mice were housed in the SPF facility of the Biomedical Research Foundation and maintained on a standard chow diet containing 5\% fat (Teklad; Harlan). All animal procedures were approved by the Bioethical Committee of the Biomedical Research Foundation and were in agreement with ethical recommendations of the European Communities Council Directive (86/609/EEC). The approved procedures for animal care and treatment were according to institutional guidelines following those of the Association for the Assessment and Accreditation of Laboratory Animal Care and the recommendations of Federation of European Laboratory Animal Science Association.

Infliximab treatment. Infliximab (Remicade) anti-huTNF- $\alpha$ antibody was purchased from a pharmaceutical supplier in a $100 \mathrm{mg}$ vial containing the lyophilized drug, which was reconstituted in sterile $0.9 \% \mathrm{NaCl}$ (saline) before use. AD/TNF transgenic 5XFAD/Tg197 mice received intraperitoneal injections of infliximab $(10 \mathrm{mg} / \mathrm{kg})$ or saline. $5 \mathrm{XFAD}$ littermates were also treated with saline. Mice were subjected to peripheral infliximab or saline treatment once a week, starting at the age of 1 month until the age of 2.5 or 4 months, when they were killed for analysis. Therefore, three mouse groups were analyzed at two different time points: (1) 5XFAD/Tg197 mice treated with infliximab (+infl), (2) 5XFAD/Tg197 mice treated with saline, and (3) 5XFAD mice treated with saline. To examine for a potential effect of infliximab on the brain phenotype of 5XFAD mice, 2 more mouse groups were generated: (1) 5XFAD mice treated with infliximab (+infl) and (2) 5XFAD mice treated with isotype control human IgG1 (R\&D Systems) (+ctrl IgG), which were analyzed at the age of 2.5 months. Five to 7 mice per group were used for analysis.

Tissue collection. Mice were anesthetized and transcardially perfused with ice-cold PBS. Immediately after death, the brains were removed and cut along the sagittal midline. Left hemibrains were snap-frozen for protein analysis. Right hemibrains were immersion-fixed in PBS-buffered $4 \%$ PFA for $48 \mathrm{~h}$ and then cryoprotected in $20 \%$ sucrose in PBS for histological analysis. Serum samples were collected from the right atrium just before the perfusion step.

Tissue processing for protein extraction. Protein extraction from brains was performed in three sequential steps. Tissues were homogenized in ice-cold PBS, containing protease inhibitors (Complete Mini Protease Inhibitor Cocktail Tablets; Roche Applied Science) with a Tissue homogenizer (Wheaton). The homogenate was centrifuged at 12,500 rpm for 45 $\min$ at $4^{\circ} \mathrm{C}$. The supernatant (PBS fraction) was removed and used to evaluate ionized calcium binding adaptor molecule 1 (Iba1) and CD206 protein levels. The pellets were resuspended in ice-cold lysis buffer (containing 10\% glycerol, $1 \%$ Triton X-100, and protease inhibitors in PBS) and centrifuged at $9000 \mathrm{rpm}$ for $10 \mathrm{~min}$ at $4^{\circ} \mathrm{C}$. The supernatant (lysis fraction) was removed and used to evaluate soluble A $\beta$, huTNF- $\alpha$, GFAP, and APP protein levels. The pellet from this step was finally solubilized in $5 \mathrm{M}$ guanidine- $\mathrm{HCl}$ (guanidine fraction) at room temperature for $3 \mathrm{~h}$ with continuous rotation to evaluate insoluble plaque-associated 
$\mathrm{A} \beta$. Brain tissue from all animals was extracted in an identical manner, and all fractions were immediately frozen at $-80^{\circ} \mathrm{C}$ until analysis.

Western blot analysis. Protein concentrations of all samples were determined using the BCA Protein Assay Kit (Thermo Scientific). Equal amounts of total protein from hemibrains were separated on SDS-PAGE $10 \%$ Tris-glycine gels (or 12\% Tris-tricine gels for Iba1) and electrophoretically transferred to nitrocellulose membranes (Protran, Whatman). Membranes were blocked with 5\% nonfat milk in TBS/Tween-20 0.05\% and then incubated with specific primary antibodies: mouse anti-GFAP (1:3000; Sigma-Aldrich), rabbit anti-Ibal (1:500; Wako), rat anti-CD206 (1:500; AbD Serotec), rabbit anti-APP (1:1500; Sigma-Aldrich), or mouse anti$\beta$ III-tubulin (1:500; Sigma-Aldrich). Membranes were then incubated with the corresponding HRP-conjugated secondary antibody (1:30001:5000; Santa Cruz Biotechnology) and developed using enhanced chemiluminescence. Densitometric analysis was performed using the National Institutes of Health ImageJ software.

ELISAs. For A $\beta$ species quantitation by ELISA, lysis (soluble $\mathrm{A} \beta$ ) and guanidine (insoluble $\mathrm{A} \beta$ ) brain homogenates were diluted with the ELISA sample buffer and sample duplicates were run on $\mathrm{A} \beta_{40^{-}}$and $\mathrm{A} \beta_{42}$-specific sandwich colorimetric ELISAs (Invitrogen) according to the manufacturer's protocol. For huTNF- $\alpha$ ELISA, lysis brain homogenates and serum samples were diluted with the ELISA assay diluent and sample duplicates were run on huTNF- $\alpha$-specific sandwich colorimetric ELISA (R\&D Systems) following the manufacturer's protocol. Optical densities at $450 \mathrm{~nm}$ of each well were read on a microplate reader (ELx800, BioTek Instruments), and sample $\mathrm{A} \beta_{40}, \mathrm{~A} \beta_{42}$ or huTNF- $\alpha$ concentrations were determined by comparison with the respective standard curves using the Gen5 software (BioTek Instruments). Brain sample values were normalized to total brain protein concentrations determined using the BCA Protein Assay Kit (Thermo Scientific). The results were calculated as mean \pm SEM for each mouse group.

Immunohistochemistry for total A $\beta$. Fixed hemibrains were cut in 40 $\mu \mathrm{m}$ sagittal free-floating sections from the genu of the corpus callosum to the most caudal hippocampus using a vibratome (Leica VT1000S). Sections were permeabilized with TBS/Triton X-100 0.1\% 3 times for $10 \mathrm{~min}$ each, incubated for 30 min with $0.6 \% \mathrm{H}_{2} \mathrm{O}_{2}$ in TBS, and washed 3 times with TBS. Antigen retrieval was performed with $98 \%$ formic acid for 5 $\mathrm{min}$, followed by 3 washes with TBS. Sections were blocked in 15\% normal goat serum (Vector Laboratories) in TBS/Triton X-100 0.1\% for $1 \mathrm{~h}$ and incubated overnight at $4{ }^{\circ} \mathrm{C}$ with the mouse monoclonal biotinylated 6E10 antibody (1:500, Covance) in 5\% normal goat serum (Vector Laboratories) in TBS/Triton X-100 0.1\%. Sections were then washed four times with TBS plus one final wash with PBS, and incubation in avidinbiotinylated HRP complex (Vectastain Standard ABC kit, Vector Laboratories) followed for $120 \mathrm{~min}$ at room temperature. Peroxidase labeling was visualized with $\mathrm{DAB} / \mathrm{Ni}$ (peroxidase substrate kit, Vector Laboratories). After a 1-2 min incubation period, sections were washed with $\mathrm{ddH}_{2} \mathrm{O}$, mounted on polylysine-coated slides (Thermo Scientific), dehydrated in increasing ethanol concentrations from $50 \%$ to $100 \%$ followed by xylene, and coverslipped with DPX medium (BDH). Imaging was performed with a DM LS2 Leica microscope, and image capture for $A \beta$ load quantitation was performed using the Leica Application Suite (version V4.6).

Thioflavine $S$ staining. The $40 \mu \mathrm{m}$ sagittal free-floating sections were incubated for $9 \mathrm{~min}$ in $1 \% \mathrm{w} / \mathrm{v}$ Thioflavine S (Sigma-Aldrich) aqueous solution and then differentiated 2 times with $80 \%$ ethanol for 3 min each, followed by another $3 \mathrm{~min}$ wash with $95 \%$ ethanol. Sections were rinsed three times with $\mathrm{ddH}_{2} \mathrm{O}$ and coverslipped with mounting medium for fluorescence (Vectashield, Vector Laboratories). Imaging for Thioflavine $S$ was performed on a Leica TCS SP 5 confocal microscope, and image captivation was performed using the Leica LAS AF Suite. Images for Thioflavine S load quantitation were captured using HCImage software in a Leica DMRA 2 microscope.

Immunofluorescence. For immunofluorescent stainings, $40 \mu \mathrm{m}$ sagittal free-floating sections were first subjected to antigen retrieval in $10 \mathrm{~mm}$ sodium citrate buffer, $\mathrm{pH}$ 6, for $30 \mathrm{~min}$ at $80^{\circ} \mathrm{C}$, then washed with PBS, blocked for $1 \mathrm{~h}$ in $10 \% \mathrm{FBS}, 1 \% \mathrm{BSA}$ in PBS/Triton X-100 0.3\%, and incubated overnight at $4^{\circ} \mathrm{C}$ with rabbit anti-Ibal (1:500; Wako), rabbit anti-CD31 (1:150; Abcam), rabbit anti- $\alpha$-smooth muscle actin ( $\alpha$-SMA) (1:250; GeneTech), rat anti-CD206 (1:250; AbD Serotec), rat anti-CD45
(1:200; ImmunoTools), rat anti-Ly6C (1:100; Santa Cruz Biotechnology), rat anti-CD68 (1:250; AbD Serotec), rabbit anti-TMEM119 (1:3, gift from Dr. BA Barres, Stanford University School of Medicine), and mouse anti-synaptophysin (1:200; Santa Cruz Biotechnology) antibodies in $1 \% \mathrm{FBS}, 1 \% \mathrm{BSA}$ in PBS/Triton X-100 0.3\%. Sections were washed with PBS and developed with anti-rabbit Cy3-conjugated (1:500; The Jackson Laboratory), anti-rat Alexa-633-conjugated (1:500; Invitrogen) or anti-rat FITC-conjugated (1:250; Oxford Biotechnology) and antimouse Alexa-546-conjugated (1:500; Invitrogen) secondary antibodies for $1 \mathrm{~h}$ at room temperature.

For infliximab immunofluorescent detection, $40 \mu \mathrm{m}$ sagittal brain sections from nonperfused infliximab-treated $5 \mathrm{XFAD} / \mathrm{Tg} 197$ mice $(n=2)$, already processed for $\mathrm{CD} 31$ and SMA immunostaining, were incubated with an anti-huIgG FITC-conjugated secondary antibody (1:250; Santa Cruz Biotechnology) for $1 \mathrm{~h}$ at room temperature. For Ibal and Thioflavine $\mathrm{S}$, double-labeling sections were finally treated with $1 \%$ Thioflavine $S$ aqueous solution for $5 \mathrm{~min}$, differentiated twice in $70 \% \mathrm{EtOH}$, and washed in PBS.

For GFAP and Thioflavine $S$ double labeling, sections were blocked for $1 \mathrm{~h}$ in TBS/Triton X-100 0.4\% supplemented with 5\% normal goat serum and immunolabeled with mouse anti-GFAP (1:500; Sigma-Aldrich) antibody in the blocking solution overnight at $4^{\circ} \mathrm{C}$. Sections were washed with TBS, developed with an anti-mouse Alexa-546-conjugated secondary antibody (1:500; Invitrogen) for $1 \mathrm{~h}$ at room temperature, and then processed for Thioflavine $S$ staining. Sections were treated with $1 \%$ Thioflavine $S$ aqueous solution for $5 \mathrm{~min}$, differentiated twice in $70 \% \mathrm{EtOH}$, and washed in PBS.

For MAP-2 immunofluorescent detection, sections were permeabilized for $1 \mathrm{~h}$ in PBS/Triton X-100 0.3\%, blocked for $1 \mathrm{~h}$ in 10\% FBS, $1 \%$ BSA in PBS/Triton X-100 0.3\%, and incubated overnight at $4^{\circ} \mathrm{C}$ with an rabbit anti-MAP-2 (1:100; Santa Cruz Biotechnology) antibody in 1\% FBS, $1 \%$ BSA in PBS/Triton X-100 0.3\%. Sections were washed with PBS and developed with an anti-rabbit Cy3-conjugated (1:500; The Jackson Laboratory) secondary antibody for $1 \mathrm{~h}$ at room temperature.

All sections were finally mounted on polylysine-coated slides (Thermo Scientific) and coverslipped with mounting medium for fluorescence (Vectashield, Vector Laboratories). Imaging was performed on a Leica TCS SP 5 confocal microscope, and images were captured using the Leica LAS AF Suite.

Image analysis and quantitation. All images were analyzed using the $\mathrm{NIH}$ ImageJ software. For the estimation of Thioflavine $S$ or $A \beta$ load, six $40 \mu \mathrm{m}$ sagittal sections $240 \mu \mathrm{m}$ apart from each other spanning all the hippocampal formation were chosen for Thioflavine $S$ staining or total $A \beta$ immunohistochemistry. After defining the region of interest (total hippocampal or cortical area), images were thresholded within a linear range and the load was expressed as the percentage area covered by Thioflavine S-positive plaques or $\mathrm{A} \beta$-positive staining ( $\%$ Thioflavine $\mathrm{S}$ or $\mathrm{A} \beta$ load).

For the quantitation of cortical CD $45^{\text {high }}$ leukocytes, five or six $40 \mu \mathrm{m}$ sagittal sections $240 \mu \mathrm{m}$ apart from each other per mouse brain were immunostained for CD45 and $10 \times$ magnification image stacks were captured on a Leica TCS SP5 confocal microscope. Cell counting was performed using the Cell Counter ImageJ plugin.

For the quantitation of cortical dendritic microtubule-associated protein 2 (MAP2) immunoreactivity, five or six $40 \mu \mathrm{m}$ sagittal sections 240 $\mu \mathrm{m}$ apart from each other per mouse brain were immunostained for MAP2 and $40 \times$ magnification image stacks were captured on a Leica TCS SP5 confocal microscope. Images were thresholded within a linear range, and the percentage area covered by MAP2-positive dendrites was measured (\% of dendritic MAP2).

For the quantitation of cortical synaptophysin intensity, five or six 40 $\mu \mathrm{m}$ sagittal sections $240 \mu \mathrm{m}$ apart from each other per mouse brain were immunostained for synaptophysin and $40 \times$ magnification image stacks were captured on a Leica TCS SP5 confocal microscope. The Raw Integrated Density of pixels was calculated for each image.

All the obtained measurements per section were then calculated as the mean value for each mouse brain and used for statistical analysis.

Statistics. All data were analyzed using one-way ANOVA followed by Tukey's post hoc test. Statistical analyses were performed using GraphPad Prism (version 5; GraphPad software for Science). Statistical significance was defined as $p<0.05$. All data are expressed as mean \pm SEM. 


\section{Results}

\section{Generation of 5XFAD/Tg197 AD/TNF transgenic mice}

To examine the effects of peripheral huTNF- $\alpha$ as a mediator of rheumatoid arthritis in $\mathrm{AD}$ pathogenesis, we crossed 5XFAD transgenic mice, a well-established AD mouse model (Oakley et al., 2006), with Tg197 mice, a huTNF- $\alpha$ expressing mouse model of arthritis (Keffer et al., 1991). Tg197 mice express a human TNF- $\alpha$ modified transgene, in which the $3^{\prime}$ - untranslated region of the human TNF- $\alpha$ gene has been replaced with the $3^{\prime}$ untranslated region of the human $\beta$-globin gene, under the guidance of the huTNF- $\alpha$ endogenous promoter. This modification results in deregulated expression of human TNF- $\alpha$ in different tissues, specifically in the joints, thymus, spleen, kidney, lung, and brain (Keffer et al., 1991). As a result of huTNF- $\alpha$ expression, Tg197 mice develop chronic inflammatory polyarthritis, starting at $\sim 1$ month of age, and show reduced weight gain (Keffer et al., 1991), probably due to impaired movement and limited access to food. Peripheral treatment of Tg197 mice with the anti-huTNF- $\alpha$ neutralizing antibody infliximab, the first anti-TNF therapeutic for RA to be successfully applied in the clinic, completely inhibits the arthritic phenotype and allows Tg197 treated mice to develop normally (http://www.biomedcode.com/gr/en/content/human-tnfdriven-polyarthritis-tg197) (Keffer et al., 1991; Shealy et al., 2002).

For the purpose of the present study, three mouse groups were generated and analyzed at the age of 2.5 and 4 months: (1) 5XFAD/Tg197 mice treated with infliximab (5XFAD/Tg197+infl), (2) 5XFAD/Tg197 mice treated with saline (5XFAD/Tg197), and (3) 5XFAD mice treated with saline (5XFAD). To examine for any potential effects of peripheral infliximab treatment on the 5XFAD amyloid phenotype, 2 more mouse groups were generated and analyzed at the age of 2.5 months: (1) 5XFAD mice treated with infliximab (5XFAD+infl) and (2) 5XFAD mice treated with isotype control human IgG1(5XFAD+ctrl IgG). All mice received weekly intraperitoneal injections with infliximab or saline or isotype control huIgG1, starting at 1 month of age, before the onset of arthritis and amyloid deposition, until analysis at the age of 2.5 or 4 months.

All 5XFAD/Tg197 mice treated with saline developed polyarthritis with visible swellings at the front and back limb joints and showed reduced weight gain similar to Tg197 siblings. Overall, 5XFAD/Tg197 mice treated with saline showed a 20\% survival rate up to the age of 4 months, probably because of decreased food intake due to the severely worsened arthritic phenotype by this age. To extend the life span of 5XFAD/Tg197 mice used in the current study up to the age of 4 months, wet mouse chow was added into the cages to provide adequate access to food. Mice of all genotypes, including treated mice, were housed together to ensure similar feeding conditions. All 5XFAD/Tg197 mice treated with infliximab did not develop the arthritic phenotype and reached the age of analysis. Only female mice were used as female 5XFAD transgenic mice develop the amyloid related phenotype 2 months earlier compared with males (Oakley et al., 2006; Sesele et al., 2013). Female 5XFAD mice start to develop amyloid deposits at 2 months, and by 4 months of age amyloid plaques have been formed throughout the hippocampus and the cortex.

\section{XFAD/Tg197 mice show a robust reduction in amyloid plaque burden, whereas peripheral infliximab treatment significantly restores the amyloid phenotype}

To examine for differences in the amyloid phenotype among the generated mouse groups, we applied Thioflavine $S$ staining and immunohistochemistry with $6 \mathrm{E} 10$ antibody on $40 \mu \mathrm{m}$ sagittal brain sections for the detection of plaques and $A \beta$ deposits. We also measured $\mathrm{A} \beta_{42}$ and $\mathrm{A} \beta_{40}$ peptide levels in brain protein extracts using specific ELISAs.

Image analysis and quantitation of Thioflavine $S$ staining that detects fibrillary deposits showed a significant decrease of amyloid plaques in the hippocampus and the cortex of 2.5 (Fig. $1 A, D, E$ ) and 4 (Fig. $1 C, F, G$ ) months old 5XFAD/Tg197 compared with $5 \mathrm{XFAD}$ mice. Amyloid plaques are almost absent in the cortex and strongly reduced in the hippocampus, mainly in the subiculum, of 5XFAD/Tg197 mice compared with agematched 5XFAD mice (Fig. $1 A, C$ ). The reduction of Thioflavine $\mathrm{S}$-positive plaque load is more prominent in the 4-month-old mice (Fig. 1C), with a 59\% decrease in the hippocampal (Fig. 1F) and a $95.4 \%$ decrease in the cortical (Fig. 1G) amyloid plaque load. Infliximab-treated 5XFAD/Tg197 mice show a trend toward elevated amyloid plaque burden in the hippocampus and cortex at the age of 2.5 months (Fig. $1 A, D, E$ ) and statistically significant increase at 4 months of age (Fig. $1 C, F, G$ ) compared with age-matched 5XFAD/Tg197 mice. Specifically, 4-monthold infliximab-treated 5XFAD/Tg197 mice show a $191.6 \%$ increase in the hippocampal (Fig. $1 F$ ) and an $892.2 \%$ increase in the cortical (Fig. $1 G$ ) amyloid plaque load compared with 5XFAD/ Tg197 mice. Overall, infliximab treatment in 5XFAD/Tg197 mice reestablishes plaque burden in the hippocampus to the levels of 5XFAD mice, and significantly restores amyloid plaque load in the cortex by the age of 4 months.

Infliximab antibody has been shown to specifically neutralize huTNF- $\alpha$ and not to cross-react with murine TNF- $\alpha$ (http://www. biomedcode.com/system/uploads/asset/data/115/Remicade-Tg197. p d f) (Irani et al., 2016; Assas et al., 2017). However, to exclude any potential effects of peripheral infliximab treatment in the 5XFAD amyloid phenotype, 5XFAD mice treated with infliximab or isotype control huIgG1were also analyzed in comparison with 5XFAD mice at the age of 2.5 months. Image analysis and quantitation of Thioflavine $\mathrm{S}$ staining revealed no differences among the 5XFAD, 5XFAD+infl, and 5XFAD + ctrl IgG brains in the hippocampus and cortex (Fig. $1 A, B, D, E$ ), suggesting that infliximab does not affect the 5XFAD amyloid phenotype. Because amyloid plaque load showed no difference among these 3 groups at the age of 2.5 months, we did not proceed to analysis of 4 -monthold 5XFAD +infl and 5XFAD + ctrl IgG mice. Thioflavine S-stained brain sections from 2.5-month-old Tg197 mice were used as negative controls (Fig. 1B).

To further examine amyloid deposition, we performed immunohistochemistry using the 6E10 antibody that detects both fibrillary and nonfibrillary $A \beta$. Similarly to the Thioflavine $S$ analysis, significantly reduced $\mathrm{A} \beta$ immunoreactivity is observed in the hippocampus and cortex of 2.5-month-old (Fig. 2A,D,E) and 4-month-old (Fig. 2C,F,G) 5XFAD/Tg197 compared with $5 X F A D$ mice. The difference is more prominent at 4 -month-old 5XFAD/Tg197 mice (Fig. 2C), which show a 68.4\% decrease in the hippocampal (Fig. $2 F$ ) and an $81 \%$ decrease in the cortical (Fig. 2G) A $\beta$ load. Infliximab-treated 5XFAD/Tg197 mice at 2.5 months of age show a trend toward increase in the hippocampal and cortical $\mathrm{A} \beta$ immunoreactivity compared with 5XFAD/Tg197 mice (Fig. $2 A, D, E$ ), whereas at 4 months this increase is statistically significant (Fig. 2C, F, G), with a $238.9 \%$ increase in the hippocampal (Fig. $2 F$ ) and a $263.5 \%$ increase in the cortical (Fig. $2 G$ ) A $\beta$ immunoreactivity compared with age-matched 5XFAD/ Tg197 mice. Therefore, infliximab treatment in 5XFAD/Tg197 mice reestablishes amyloid deposition in the hippocampus to the levels of 5XFAD mice, and significantly restores $A \beta$ load in the cortex by the age of 4 months. Image analysis and quantitation of 
A
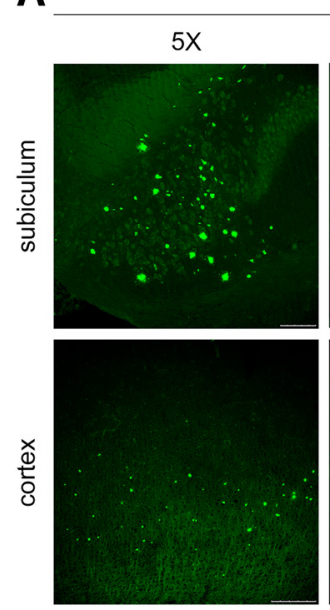

B
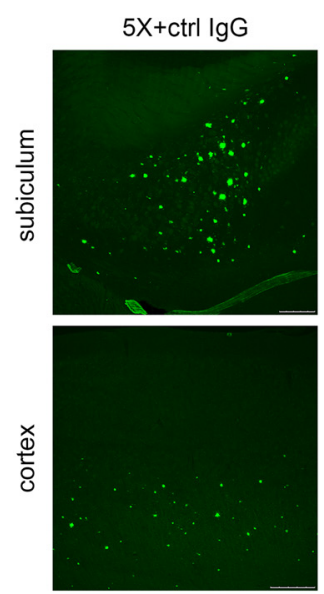

$2.5 \mathrm{mo}$
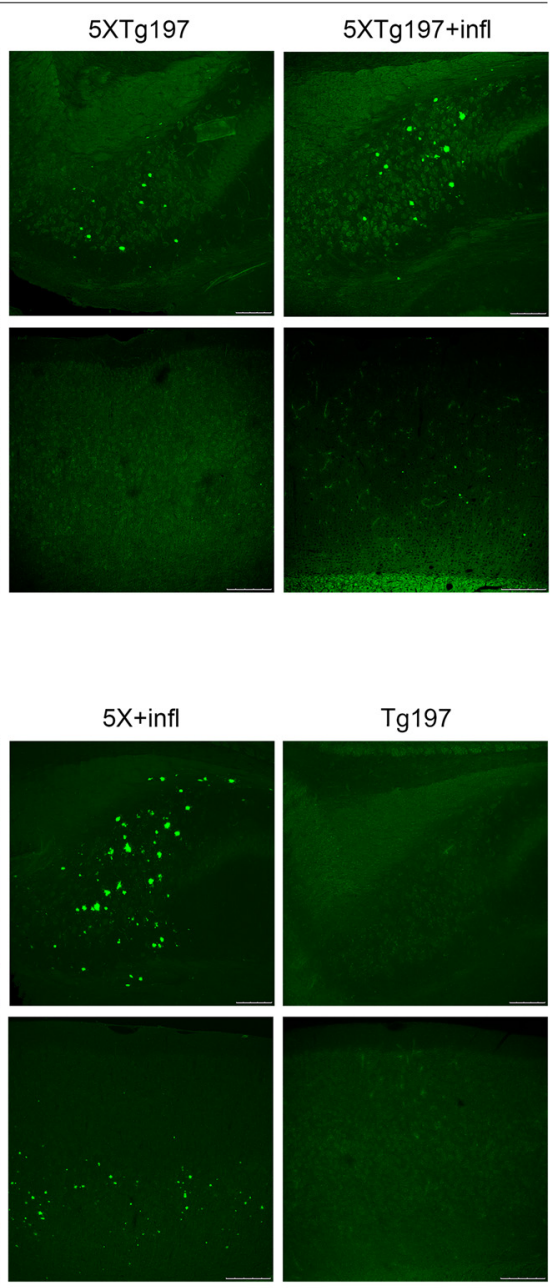

\section{$5 \mathrm{XTg} 197+\mathrm{infl}$}
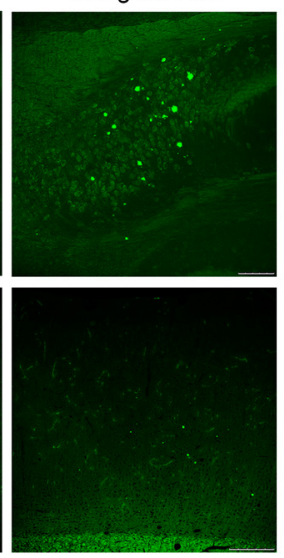

\section{D}
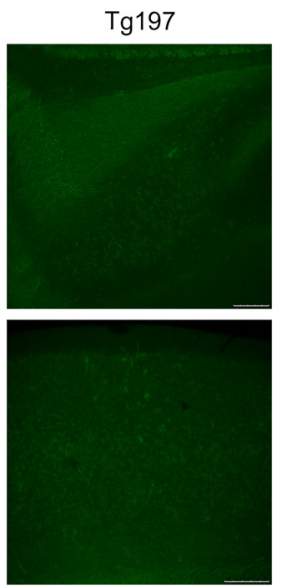

E
C

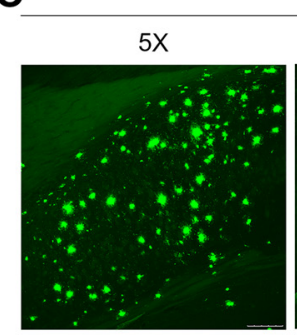

4 mo
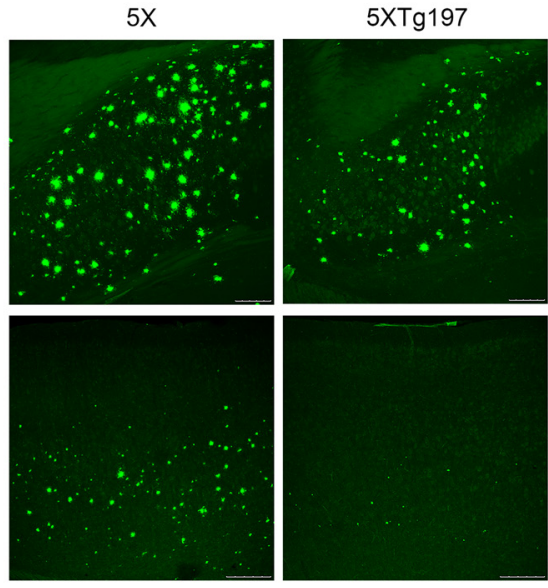

5XTg197+infl
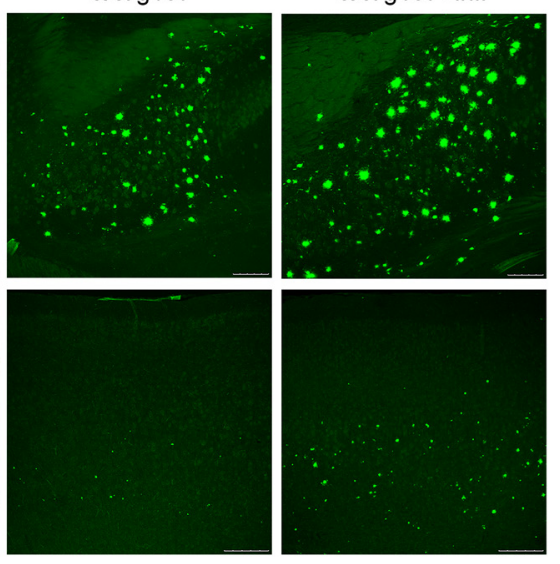

$2.5 \mathrm{mo}$
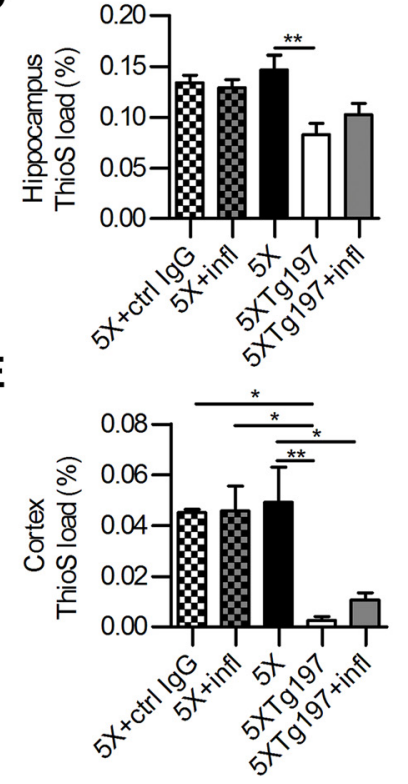

$\mathbf{F}$

$4 \mathrm{mo}$

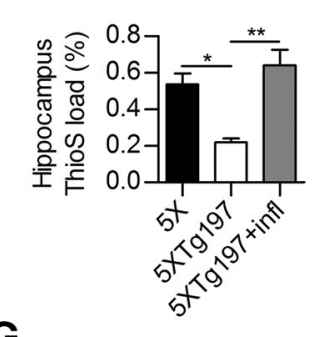

G
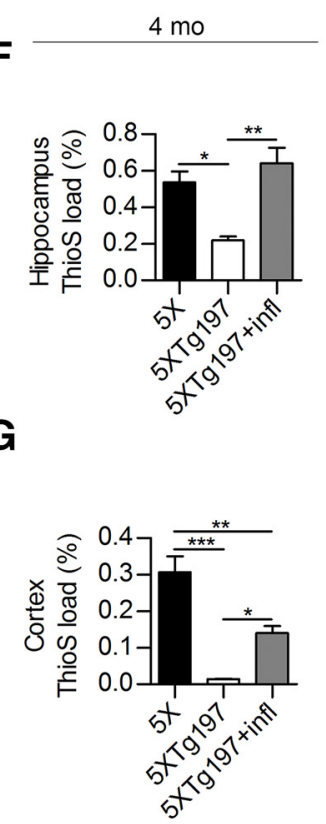

Figure 1. huTNF- $\alpha$ expression strongly reduces Thioflavine S-positive plaques, whereas peripheral infliximab treatment significantly restores amyloid plaque burden in 5XFAD/Tg197 mice. $A-C$, Thioflavine S staining of sagittal brain sections of 2.5-month-old (A) and 4-month-old (C) 5XFAD, 5XFAD/Tg197, and infliximab-treated ( + infl) 5XFAD/Tg197 mice was performed to detect fibrillary amyloid plaques. 5XFAD mice treated with isotype control hulgG1 ( + ctrl lgG) or infliximab ( + infl) were also analyzed at the age of 2.5 months (B). Brain sections of 2.5 -month-old Tg197 mice were used as negative controls $(\boldsymbol{B})$. Representative pictures of the subiculum of the hippocampus and the cortex are shown for each mouse group. Scale bars: subiculum, $100 \mu \mathrm{m}$; cortex, $250 \mu \mathrm{m} . \boldsymbol{D}, \boldsymbol{E}, \boldsymbol{F}, \boldsymbol{G}$, Quantitation of Thioflavine S-positive amyloid plaque load in the hippocampi and cortices of 2.5-month-old $(\boldsymbol{D}, \boldsymbol{E})$ and 4 -month-old $(\boldsymbol{F}, \boldsymbol{G})$ mice is expressed as the percentage area of positive staining. A significant reduction of plaque burden was revealed in 5XFAD/Tg197 mice of both ages compared with 5XFAD mice, whereas peripheral infliximab treatment of 5XFAD/Tg197 mice resulted in significantly increased Thioflavine Sload by the age of 4 months both in the hippocampus and cortex. No difference was detected among the groups of 2.5 -month-old 5XFAD + ctrl lgG, 5XFAD + infl, and 5XFAD mice. Analysis was performed using ImageJ software. Data are mean \pm SEM; $n=5-7$ per group. * $p<0.05$ (one-way ANOVA followed by Tukey's post hoc test). ${ }^{* *} p<0.01$ (one-way ANOVA followed by Tukey's post hoc test). ${ }^{* * *} p<0.001$ (one-way ANOVA followed by Tukey's post hoc test).

$\mathrm{A} \beta$ immunoreactivity in 2.5-month-old 5XFAD + infl and 5XFAD + ctrl IgG brains showed no difference compared with 5XFAD mice (Fig. $2 \mathrm{~A}, B, D, E)$. $\mathrm{A} \beta$ immunostained brain sections from 2.5month-old Tg197 mice were used as negative controls (Fig. 2B).

Next, we examined the levels of $\mathrm{A} \beta_{42}$ and $\mathrm{A} \beta_{40}$ peptides in the guanidine (insoluble $\mathrm{A} \beta$ ) and lysis (soluble $\mathrm{A} \beta$ ) fractions of brain protein extracts using ELISA. Total (insoluble and soluble) $\mathrm{A} \beta_{42}$ and $\mathrm{A} \beta_{40}$ levels are reduced in 5XFAD/Tg197 compared with 5XFAD brains both for the 2.5-month-old (Fig. 3A-C) and 4 -month-old (Fig. $3 D-G$ ) mice. A statistically significant reduction in the levels of insoluble $\mathrm{A} \beta_{42}$ (Fig. $3 A, D$ ) and $\mathrm{A} \beta_{40}$ (Fig. $3 C, F)$ was revealed in $5 \mathrm{XFAD} / \mathrm{Tg} 197$ mice of both ages compared with 5XFAD mice, which reflects the observed decrease in fibril- lary amyloid deposits between the two groups. Soluble $A \beta_{42}$ shows a trend toward reduction at 2.5-month-old 5XFAD/Tg197 mice (Fig. $3 B$ ), whereas soluble $A \beta_{42}$ and $A \beta_{40}$ levels are significantly decreased at 4 months (Fig. $3 E, G$ ). In 2.5 -month-old infliximab-treated 5XFAD/Tg197 mice, total $\mathrm{A} \beta_{42}$ (Fig. $3 A, B$ ) and insoluble $\mathrm{A} \beta_{40}$ (Fig. $3 C$ ) levels show a trend toward increase compared with 5XFAD/Tg197 mice. At the age of 4 months, $5 X F A D / T g 197+$ infl mice show significantly increased total $\mathrm{A} \beta_{42}$ (Fig. $3 D, E$ ) and insoluble $\mathrm{A} \beta_{40}$ (Fig. $3 F$ ) levels compared with 5XFAD/Tg197 mice. Soluble $\mathrm{A} \beta_{40}$ levels of 4-month-old infliximabtreated 5XFAD/Tg197 mice showed only a trend toward increase (Fig. $3 G$ ). Thus, peripheral infliximab treatment of 5XFAD/ $\mathrm{Tg} 197$ mice resulted in an increase of $\mathrm{A} \beta$ levels by the age of 4 
A
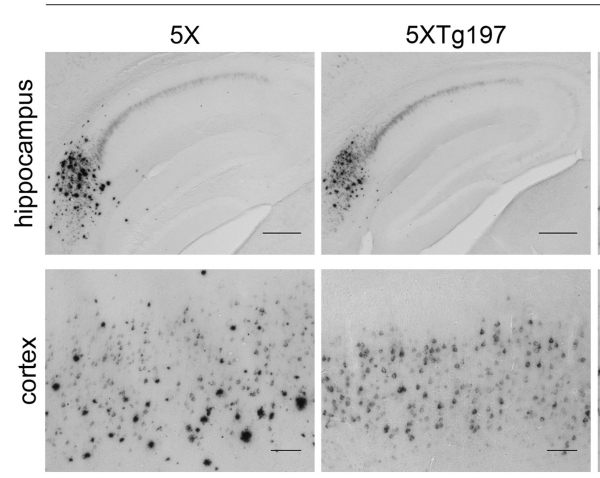

B

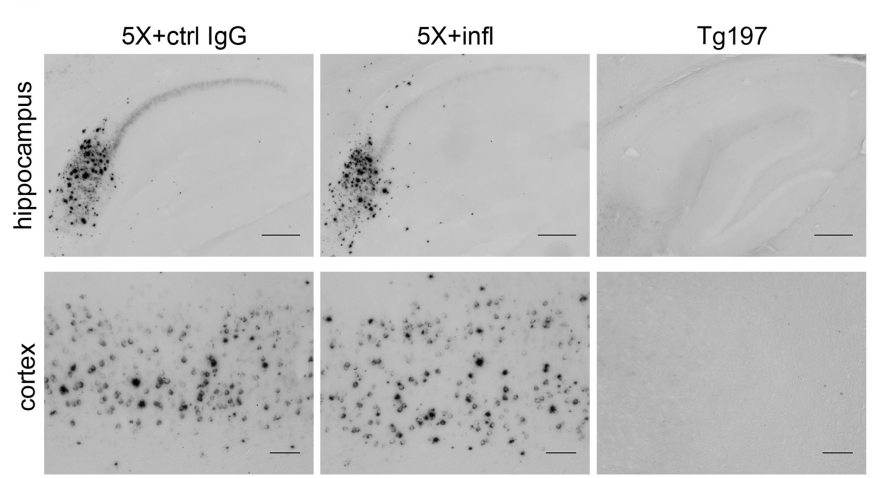

C

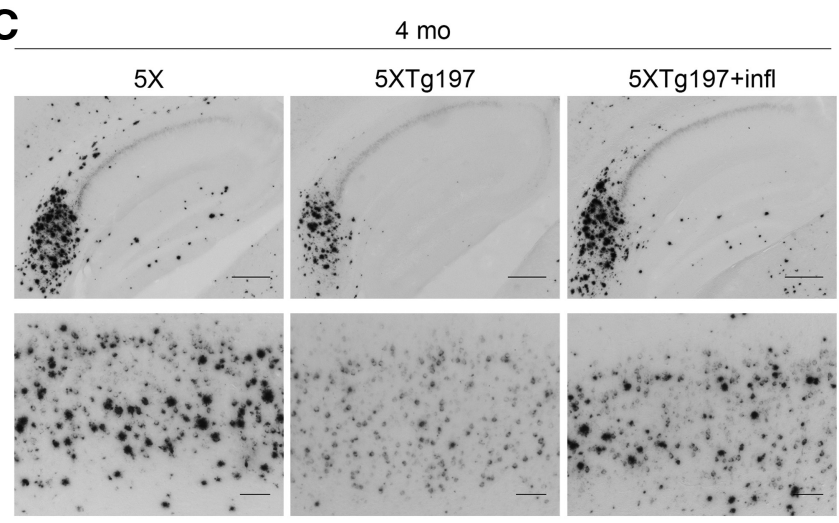

D
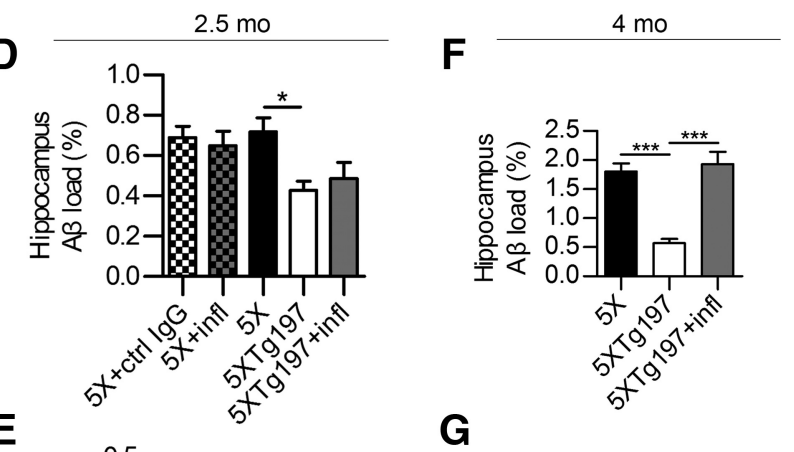

G
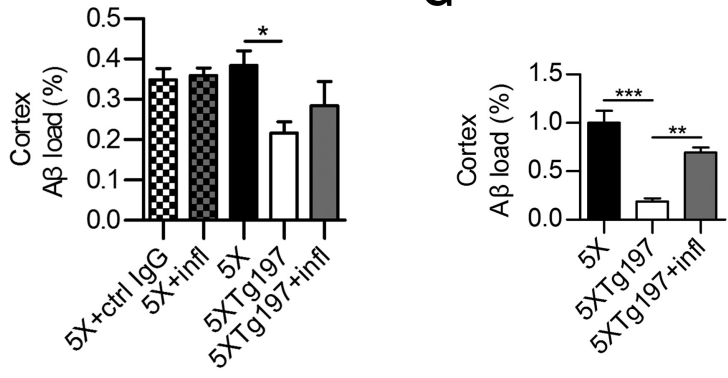

Figure 2. $5 X F A D / T g 197$ mice display reduced $A \beta$ deposition that is significantly increased upon peripheral infliximab treatment. $A-C$, Immunohistochemistry for the detection of total $A \beta(6 E 10$ antibody) in sagittal brain sections of 2.5-month-old (A) and 4-month-old (C) 5XFAD, 5XFAD/Tg197, and infliximab-treated ( + infl) 5XFAD/Tg197 mice. 5XFAD mice treated with isotype control hulgG1 ( + ctrl lgG) or infliximab ( + infl) were also analyzed at the age of 2.5 months $(\boldsymbol{B})$. Brain sections of 2.5-month-old $\mathrm{Tg} 197$ mice were used as negative controls (B). Representative pictures of the hippocampus and cortex are shown for each mouse group. Scale bars: hippocampus, $250 \mu \mathrm{m}$; cortex, $100 \mu \mathrm{m} . \boldsymbol{D}, \boldsymbol{E}, \boldsymbol{F}, \boldsymbol{G}$, Quantitation of $A \beta$ immunoreactivity in the hippocampi and cortices of 2.5-month-old $(\boldsymbol{D}, \boldsymbol{E})$ and 4 -month-old $(\boldsymbol{F}, \boldsymbol{G})$ mice is expressed as the percentage area of positive staining. A significant reduction of $\mathrm{A} \beta$ load was revealed in $5 \mathrm{XFAD} / \mathrm{Tg} 197$ mice of both ages compared with $5 \mathrm{XFAD}$ mice, whereas peripheral infliximab treatment of 5XFAD/Tg197 mice resulted in significantly increased $\mathrm{A} \beta$ immunoreactivity by the age of 4 months both in the hippocampus and cortex. No difference was detected among the groups of 2.5-month-old 5XFAD + ctrl lgG, 5XFAD + infl, and 5XFAD mice. Analysis was performed using Image software. Data are mean \pm SEM; $n=5-7$ per group. ${ }^{*} p<0.05$ (one-way ANOVA followed by Tukey's post hoc test). ${ }^{* *} p<0.01$ (one-way ANOVA followed by Tukey's post hoc test). ${ }^{* * *} p<0.001$ (one-way ANOVA followed by Tukey's post hoc test).

months. In addition, total $\mathrm{A} \beta_{42}$ and $\mathrm{A} \beta_{40}$ levels in 2.5-month-old $5 \mathrm{XFAD}+$ infl and $5 \mathrm{XFAD}+\mathrm{ctrl}$ IgG mice showed no difference compared with $5 \mathrm{XFAD}$ mice (Fig. $3 A-C$ ). Soluble $\mathrm{A} \beta_{40}$ levels of 2.5-month-old mice are below the detection threshold and are not shown.

Overall, these data provide evidence that huTNF- $\alpha$ expression in 5XFAD/Tg197 mice protects against amyloid deposition, whereas peripheral infliximab treatment reverses this effect and significantly restores amyloid load by the age of 4 months. Infliximab shows a huTNF-specific effect as it does not affect the amyloid phenotype of 5XFAD mice.

5XFAD/Tg197 mice display robust microglial and astrocytic activation that is strongly reduced upon peripheral infliximab treatment

5XFAD mice have been shown to have extended neuroinflammatory responses displaying a significant increase in microglial and astrocytic activation that is associated with age and amyloid de- position (Oakley et al., 2006). To evaluate the potential effect of huTNF- $\alpha$ expression and peripheral infliximab treatment in the activation of glial cells, we analyzed 5XFAD/Tg197, infliximabtreated 5XFAD/Tg197, and 5XFAD brains for microglial (Iba1) and astrocytic (GFAP) markers. Single Tg197 transgenic as well as wild-type C57BL/6 mice were also included in the analysis to examine the consequences of huTNF- $\alpha$ expression on glial activation independently of amyloid deposition.

Confocal analysis of $40 \mu \mathrm{m}$ sagittal brain sections doublestained for Ibal and Thioflavine $S$ showed a significant increase of reactive microglia in 2.5-month-old (Fig. 4A, top panels) and 4-month-old (Fig. 4A, bottom panels) 5XFAD/Tg197 mice, compared with age-matched 5XFAD mice. In 5XFAD brains, activated microglia surround amyloid plaques (focal activation pattern) and show amoeboid morphology (Fig. 4A). In contrast, in 5XFAD/Tg197 brains, highly reactive microglial cells are scattered throughout the brain parenchyma (diffused activation pattern) and acquire an elongated morphology with short thick 
$2.5 \mathrm{mo}$

A

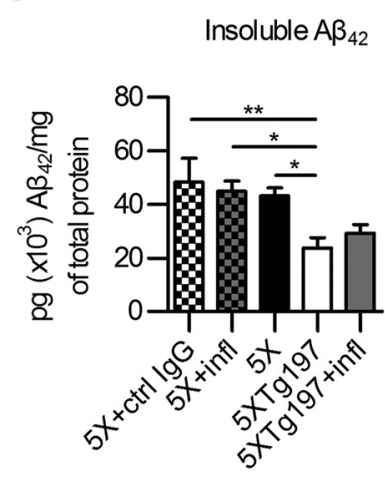

B

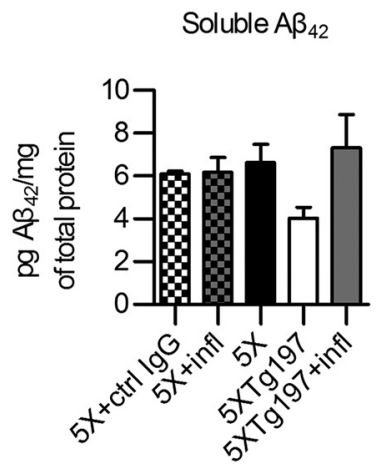

C

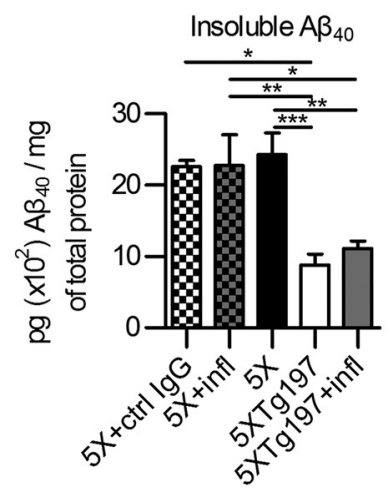

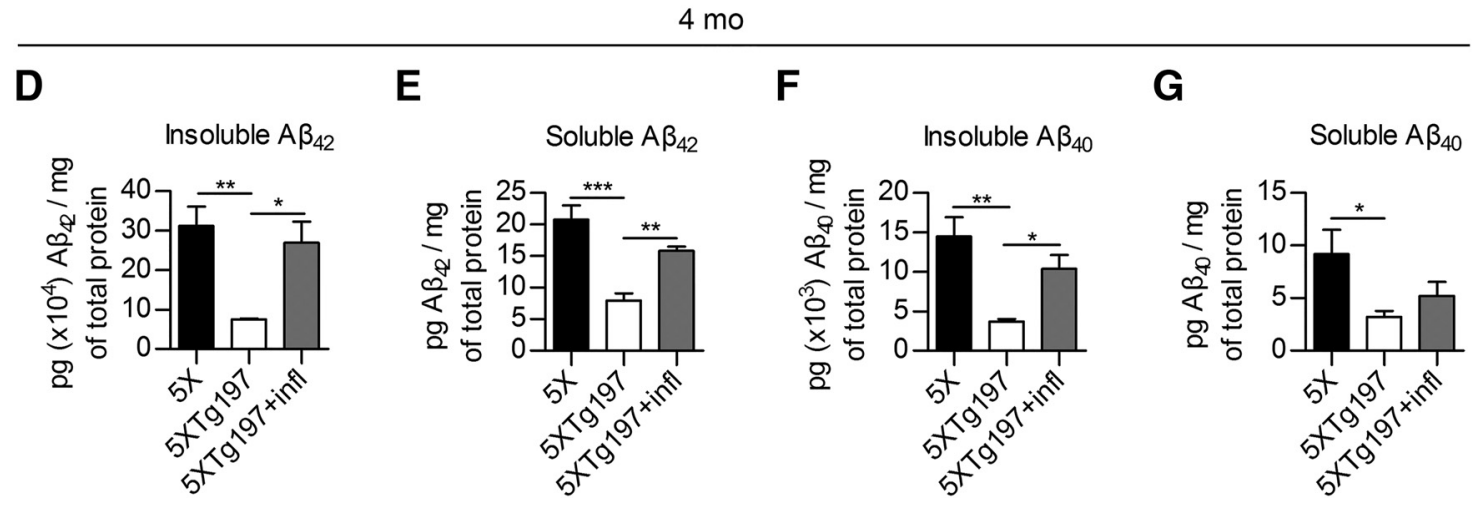

Figure 3. Expression of huTNF- $\alpha$ in $5 X F A D / T g 197$ mice leads to decreased $A \beta_{42}$ and $A \beta_{40}$ levels that are elevated upon peripheral infliximab treatment. $A-G$, ELISA measurement of insoluble and soluble $A \beta_{42}(\boldsymbol{A}, \boldsymbol{B}, \boldsymbol{D}, \boldsymbol{E})$ and $A \beta_{40}(\boldsymbol{C}, \boldsymbol{F}, \boldsymbol{G})$ levels in the guanidine and lysis brain extracts of 2.5-month-old $(\boldsymbol{A}-\boldsymbol{C})$ and 4-month old (D-G) 5XFAD, 5XFAD/Tg197, and infliximab-treated ( + infl) 5XFAD/Tg197 mice. 5XFAD mice treated with isotype control hulgG1 ( + ctrl lgG) or infliximab (+infl) were also analyzed at the age of 2.5 months. 0verall, quantitation revealed a significant reduction of $A \beta_{42}$ and $A \beta_{40}$ levels in 5XFAD/Tg197 mice of both ages compared with 5XFAD mice $(A-G)$, whereas peripheral infliximab treatment of the 5 XFAD/Tg197 mice resulted in significantly increased $A \beta_{42}$ and $A \beta_{40}$ levels by the age of 4 months $(\boldsymbol{D}-\boldsymbol{G})$. No difference was detected among the groups of 2.5 -month-0ld 5XFAD + ctrl lgG, 5XFAD + infl, and 5XFAD mice ( $\left.A-C\right)$. Soluble $A \beta_{40}$ levels of 2.5 -month-old mice were below detection limit and are not shown. Data are mean \pm SEM; $n=5$ or 6 per group. ${ }^{*} p<0.05$ (one-way ANOVA followed by Tukey's post hoc test). ${ }^{* *} p<0.01$ (one-way ANOVA followed by Tukey's post hoc test). ${ }^{* * *} p<0.001$ (one-way ANOVA followed by Tukey's post hoc test).

processes, although they do not show amoeboid plaque-associated morphology (Fig. 4A, arrowheads). To confirm that the robust microglial activation in $5 \mathrm{XFAD} / \mathrm{Tg} 197$ mice is caused by huTNF- $\alpha$, we performed Ibal immunofluorescence in brain sections of 2.5month-old Tg197 mice and compared them with C57BL/6 mice. Confocal analysis revealed that Tg197 mice show diffused pattern of microglial activation that is similar to 5XFAD/Tg197 mice (Fig. 5A). To evaluate whether microglial activation precedes the onset of amyloid deposition and peripheral infliximab treatment we analyzed young $\operatorname{Tg} 197$ brains and observed early activation of microglia at 1 month of age, compared with C57BL/6 mice (Fig. 5C). In infliximab-treated 5XFAD/Tg197 mice, microglial activation is significantly reduced compared with 5XFAD/Tg197 mice at 2.5 (Fig. $4 A$, top panels) and 4 (Fig. $4 A$, bottom panels) months of age. Microglia in infliximab-treated 5XFAD/Tg197 brains can be divided in two categories: (1) microglia retaining the 5XFAD/Tg197 morphology but showing notably reduced size and fluorescence intensity of Ibal staining; and (2) plaque-associated more amoeboid-like microglia (Fig. 4A). To quantify the levels of Iba1, we performed Western blot analysis on total brain protein extracts from 2.5-month-old 5XFAD, 5XFAD/Tg197, and infliximab-treated 5XFAD/Tg197 mice. Analysis of Ibal protein levels confirmed the differences in microglial activation observed with immunofluorescence among the three mouse groups. 5XFAD/Tg197 brains show a statistically significant increase of Ibal levels that decrease upon peripheral infliximab treatment (Fig. 4B).

Next, we examined astrocytic activation in the three studied mouse groups. Confocal analysis of $40 \mu \mathrm{m}$ sagittal brain sections double-stained for GFAP and Thioflavine $S$ revealed a significant increase in reactive astrocytes in 5XFAD/Tg197 mice compared with 5XFAD mice at 2.5 months (Fig. $4 C$, top panels) and 4 months (Fig. 4C, bottom panels) of age. A limited number of hypertrophic activated astrocytes are detected around amyloid plaques in 5XFAD mice, whereas in 5XFAD/Tg197 mice reactive astrocytes are densely dispersed in the brain parenchyma (Fig. $4 C$ ) and appear to interact with the adjacent plaques (Fig. 4C, arrowheads). To confirm that the robust astrocytic activation in $5 \mathrm{XFAD} / \mathrm{Tg} 197$ mice is caused by huTNF- $\alpha$, we performed GFAP immunofluorescence in brain sections of 2.5-month-old Tg197 mice and compared them with C57BL/6 mice. Confocal analysis showed that Tg197 mice display diffused astrocytosis that is similar to 5XFAD/Tg197 mice (Fig. 5B). Consistent with the microglial activation in young Tg197 brains, immunofluorescence imaging for GFAP in 1-month-old Tg197 mice also revealed early activation of astrocytes compared with C57BL/6 mice (Fig. 5D). Upon peripheral infliximab treatment, astrocytic activation is significantly decreased with fewer cells of reduced size and fluorescent intensity detected, which still retain a diffused pattern in 
A

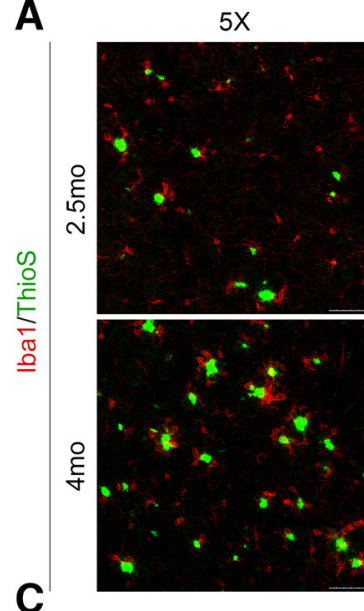

C
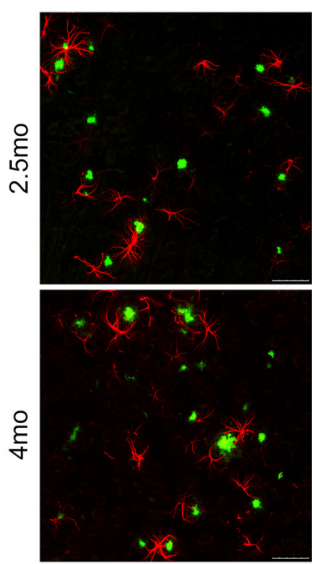

$5 \times \operatorname{Tg} 197$
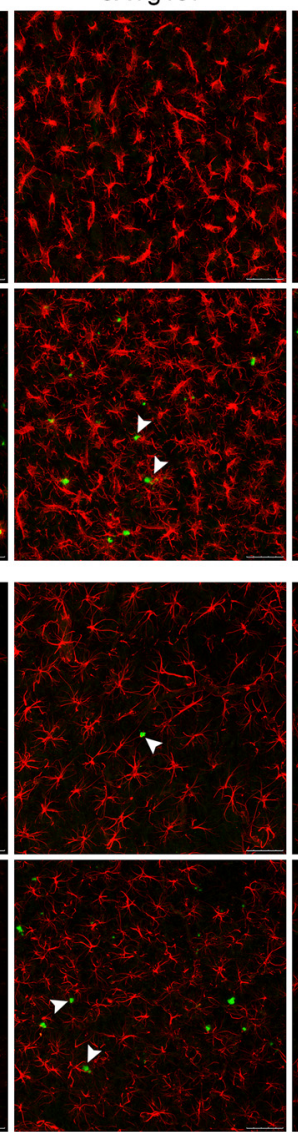

5XTg197+infl
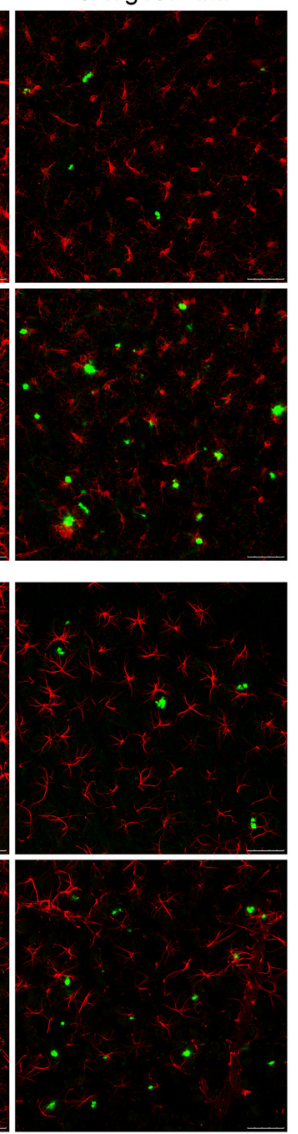

B

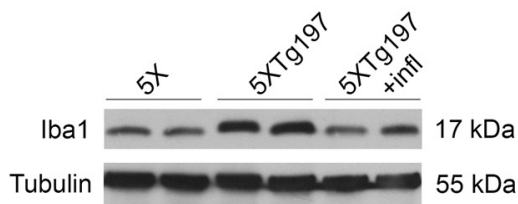

D
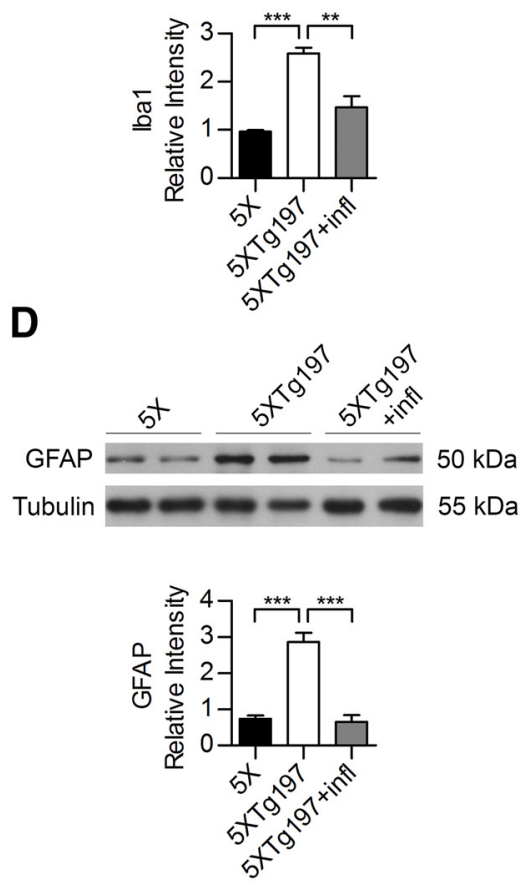

Figure 4. huTNF- $\alpha$ expression in 5XFAD/Tg197 mice causes robust glial activation that is significantly decreased upon peripheral infliximab treatment. $A, C$, Immunofluorescent detection of Iba1-positive microglia $(\boldsymbol{A})$ and GFAP-positive astrocytes $(\boldsymbol{C})$ in sagittal brain sections of 2.5- and 4-month-old 5XFAD, 5XFAD/Tg197, and infliximab-treated (+infl) 5XFAD/Tg197 mice. Sections were also stained for amyloid plaques with Thioflavine S. 5XFAD mice display focal gliosis, with periplaque activation of microglia and astrocytes, whereas 5XFAD/Tg197 mice show diffused gliosis, with dispersed pattern of glial activation. In infliximab-treated 5XFAD/Tg197 mice, although microglial and astrocytic activation appears similar to 5XFAD controls, the immunoreactivity pattern remains diffused. Representative pictures of the cortex of 2.5- and 4-month-old mice are shown for each group. Scale bars, $50 \mu \mathrm{m}$. $\boldsymbol{B}, \boldsymbol{D}$, Western blot analysis of lba1 (B) and GFAP (D) brain protein levels in 2.5-month-old 5XFAD, 5XFAD/Tg197, and infliximab-treated (+infl) 5XFAD/Tg197 mice. 5XFAD/Tg197 mice show strongly increased levels of Iba1 and GFAP that are significantly reduced upon peripheral infliximab treatment. Quantitation was performed with densitometric analysis using ImageJ software. Data are mean \pm SEM; $n=2$ per group; experiment repeated 3 times using different samples. ${ }^{* *} p<0.01$ (one-way ANOVA followed by Tukey's post hoc test). ${ }^{* *} p<0.001$ (one-way ANOVA followed by Tukey's post hoc test).

the brain parenchyma similarly to the 5XFAD/Tg197 mice (Fig. $4 C)$. In 5XFAD/Tg197+infl mice, plaque-associated astrocytes that are less hypertrophic compared with the 5XFAD are also observed (Fig. 4C). To quantify GFAP levels, we performed Western blotting on total brain protein extracts from 2.5-month-old 5XFAD, 5XFAD/Tg197, and infliximab-treated 5XFAD/Tg197 mice. Subsequent analysis showed a statistically significant increase of GFAP protein levels in 5XFAD/Tg197 mice that decrease substantially upon peripheral infliximab treatment (Fig. $4 D$ ).

Interestingly, Western blot analysis for both Ibal and GFAP levels shows that peripheral infliximab treatment is able to reduce glial activation to a great extent, close to the levels of 5XFAD brains, despite the differences in cell morphology and distribution throughout the brain. Notably, no significant differences were observed in Ibal and GFAP protein levels between the 2.5and 4-month-old 5XFAD/Tg197 or infliximab-treated 5XFAD/ Tg197 mice, as well as between 2.5-month-old Tg197 and 5XFAD/Tg197 mice (data not shown). In summary, these data demonstrate that huTNF- $\alpha$ expression in Tg197 and 5XFAD/ Tg197 mice induces robust gliosis. Microglial and astrocytic activation is already observed by the early age of 1 month, just before starting peripheral infliximab treatment, implying that infliximab suppresses glial activation rather than prevents the development of the neuroinflammatory phenotype.

Infliximab reduces only peripheral and not brain huTNF- $\alpha$ levels in 5XFAD/Tg197 mice and is detected only in the cerebral blood vessels and not into the brain parenchyma Initial mRNA analysis in Tg197 mice had revealed that huTNF- $\alpha$ is expressed, apart from the joints, in several other tissues including the brain (Keffer et al., 1991). To examine whether the observed alterations in the amyloid and neuroinflammatory phenotype of 5XFAD/ Tg197 and infliximab-treated 5XFAD/Tg197 mice correlate with changes in the peripheral or brain huTNF- $\alpha$ levels, we measured huTNF- $\alpha$ in the sera and brain protein extracts using a huTNF- $\alpha$ specific ELISA. Analysis confirmed huTNF- $\alpha$ expression in the serum and brain of 2.5- and 4-month-old 5XFAD/Tg197 mice (Fig. $6 A, B)$. Upon peripheral infliximab treatment, serum huTNF- $\alpha$ is significantly reduced in infliximab-treated 5XFAD/Tg197 mice (Fig. $6 A$ ), whereas brain huTNF- $\alpha$ remains unchanged (Fig. 6B). Notably, serum or brain huTNF- $\alpha$ remains at the same levels within 5XFAD/Tg197 or infliximab-treated 5XFAD/Tg197 mice independently of age. These results show that the neutralizing effect of infliximab is restricted only in the periphery, suggesting that infliximab 
$2.5 \mathrm{mo}$
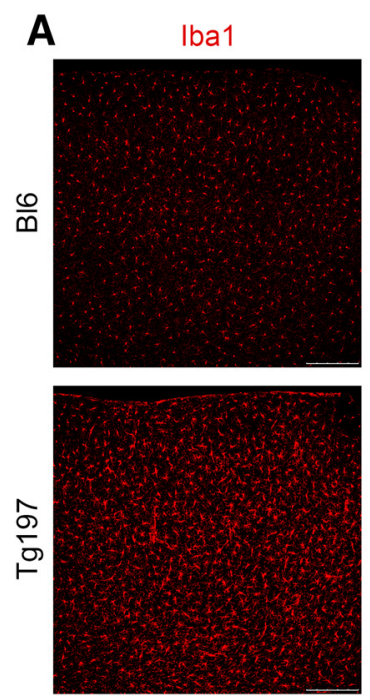

B
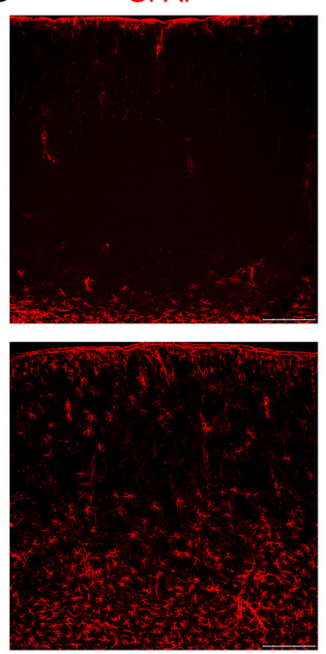

$1 \mathrm{mo}$

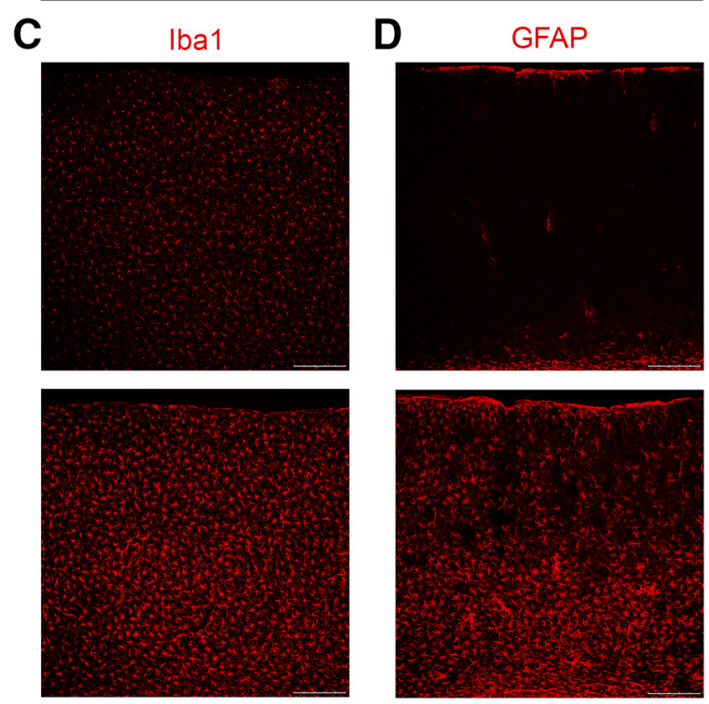

Figure 5. Tg197 mice display increased glial activation compared with C57BL/6 mice, by the age of 1 month. $A-D$, Immunofluorescent detection of lba1-positive microglia $(A, C)$ and GFAP-positive astrocytes $(B, D)$ in sagittal brain sections of 2.5- and 1-month-old Tg197 and C57BL/6 control mice. Diffused patterns of glial activation observed in 5XFAD/Tg197 mice comprise a feature of the Tg197 phenotype that develops as early as 1 month of age, before the onset of amyloid plaque formation or infliximab treatment. Representative pictures of the cortex are shown for each group. Scale bars, $250 \mu \mathrm{m}$.

cannot reach the brain parenchyma, which is expected because high molecular weight molecules such as antibodies cannot cross the blood-brain barrier (BBB). To confirm this, we examined whether infliximab can be detected in the brain of 5XFAD/Tg197 mice. For this purpose, we immunostained $40 \mu \mathrm{m}$ sagittal brain sections of infliximab-treated 5XFAD/Tg197 mice using an FITC-labeled antihuIgG1 antibody. Double immunofluorescence for infliximab and CD31 (platelet endothelial cell adhesion molecule 1) or $\alpha$-SMA revealed localization of infliximab inside brain blood vessels (Fig. $6 C, D)$. This finding shows that infliximab is not able to cross the BBB and is only detected inside the cerebral vessel lumen and not the brain parenchyma of 5XFAD/Tg197 mice.

5XFAD/Tg197 mice show intensely increased CD206-positive leptomeningeal and perivascular macrophages that are significantly decreased upon peripheral huTNF- $\alpha$ inhibition by infliximab

Our analysis has shown that, although peripheral infliximab treatment does not affect huTNF- $\alpha$ levels in the 5XFAD/Tg197 brain, it strongly reduces microglial and astrocytic activation and exacerbates amyloid deposition. We hypothesized that changes in glial activation may be mediated by BBB-associated cells that are located around blood vessels and can be directly affected by peripheral huTNF- $\alpha$ levels. It has been reported that microglia can respond to circulating cytokines through several routes, including communication with the stimulated endothelium and perivascular macrophages or the circumventricular organs (Calsolaro and Edison, 2016). Moreover, in peripheral inflammatory conditions, TNF- $\alpha$ has been reported to be involved in the recruitment of peripheral monocytes in the brain that can give rise to perivascular macrophages, a BBB-associated cell population (Audoy-Rémus et al., 2008). To examine whether peripheral huTNF- $\alpha$ is able to regulate perivascular macrophages, we immunostained brain sections of C57BL/6, Tg197, 5XFAD, 5XFAD/ Tg197, and infliximab-treated 5XFAD/Tg197 mice using a CD206specific antibody. CD206 is a mannose receptor used as a brain perivascular macrophage marker (Hawkes and McLaurin, 2009; Park et al., 2011). Double immunofluorescence was performed for CD206 and the microglial marker Ibal or the blood vessel markers
CD31 or $\alpha$-SMA. Confocal analysis revealed an increase in CD206positive macrophages in the leptomeninges (Fig. $7 A, B$, arrowheads) and the perivascular space (Fig. $7 B, C$, arrows) of 5XFAD/Tg197 brains compared with the 5XFAD. Similarly to 5XFAD/Tg197 mice, single transgenic Tg197 mice show elevated CD206-positive macrophages compared with $\mathrm{C} 57 \mathrm{BL} / 6$ mice (Fig. $7 A-C$ ), suggesting that the increase of this cell population results from huTNF- $\alpha$ expression. Upon peripheral infliximab treatment in 5XFAD/Tg197 mice, a strong decrease in CD206-positive macrophage numbers and fluorescence intensity is observed both in the leptomeninges (Fig. $7 A, B$, arrowheads) and brain blood vessels (Fig. $7 B, C$, arrows). No colocalization was observed between CD206-positive macrophages and Iba1-positive microglia (Fig. 7A), implying that CD206-positive macrophages consist a discrete population from Iba1-positive microglia. To quantify the effect of peripheral huTNF- $\alpha$ on CD206positive macrophages, we also performed Western blot analysis of CD206 levels in total brain protein extracts from C57BL/6, Tg197, 5XFAD, 5XFAD/Tg197, and infliximab-treated 5XFAD/Tg197 mice. Quantitation of CD206 levels revealed a robust increase in Tg197 and 5XFAD/Tg197 mice compared with C57BL/6 and 5XFAD mice (Fig. 7D). Surprisingly, the presence of the 5XFAD transgene in 5XFAD/Tg197 mice results in a statistically significant increase of CD206 protein levels compared with Tg197 mice (Fig. 7D). Infliximab-treated 5XFAD/Tg197 mice showed a significant reduction of CD206 toward the levels of 5XFAD mice (Fig. 7D). Our results show that peripheral huTNF- $\alpha$ levels play a major role in the regulation of leptomeningeal and perivascular macrophages. Moreover, the further increase of CD206-positive macrophages in 5XFAD/Tg197 mice compared with the Tg197 suggests that this immune cell population is involved in amyloid pathology, as it has been also proposed by others (Lai and McLaurin, 2012; MeyerLuehmann and Prinz, 2015).

5XFAD/Tg197 brains display increased CD45 $5^{\text {high }}$ microglia and infiltrating leukocytes that are substantially reduced upon peripheral inhibition of huTNF- $\alpha$ by infliximab CD45-positive infiltrating leukocytes and periplaque activated microglia have been detected in both human and mouse AD 
brains (Masliah et al., 1991; Cameron and Landreth, 2010). Moreover, increased CD45-positive monocytes/macrophages have been detected in the brain of mice with inflammatory liver injury or arthritis (D'Mello et al., 2009; Park et al., 2011). These studies suggest that recruitment of CD45-positive cells in the mouse brain can be triggered both in $\mathrm{AD}$ and peripheral inflammation. To examine for a similar effect in our TNF transgenic mice either in the presence or in the absence of amyloid pathology, we performed immunofluorescence for CD45 (leukocyte common antigen) in brain sections of C57BL/6, Tg197, 5XFAD, 5XFAD/Tg197, and infliximabtreated 5XFAD/Tg197 mice. Because CD45 is also expressed by endogenous microglia, we also double-labeled brain sections for CD45/Iba1.

Confocal analysis revealed increased CD45 expression (CD45 high) in reactive Ibal-positive microglia of Tg197 and 5XFAD/ Tg197 mice compared with the C57BL/6 and 5XFAD (Fig. 8A,B). In C57BL/6 and $5 \mathrm{XFAD}$ mice, we observe $\mathrm{CD} 45^{\text {low }}$ resting microglial cells with only few $\mathrm{CD} 45^{\text {high }}$ activated microglia detected in the 5XFAD brain (Fig. 8A) that are associated with Thioflavine S-positive plaques (Fig. 8E, arrowheads). Infliximab-treated 5XFAD/ Tg197 mice display decreased CD $45^{\text {high }}$ Ibal-positive reactive microglia compared with 5XFAD/Tg197 mice (Fig. 8A,B).

Importantly, we detected dramatically increased CD $45^{\text {high }}$ round-shaped leukocytes that are Iba1-negative in the cortex and leptomeninges of Tg197 and 5XFAD/ Tg197 brains compared with C57BL/6 and 5XFAD mice (Fig. $8 A, B$, arrowheads), implying that recruitment of these peripherally derived immune cells in the brain is caused by huTNF- $\alpha$ expression. To confirm that CD $45^{\text {high }}$ leukocytes infiltrate the brain of the analyzed mouse groups, we performed double immunofluorescence for CD45 and CD31 blood vessel marker. Indeed, Tg197 and 5XFAD/Tg197 mice show increased infiltration of CD45 $5^{\text {high }}$ leukocytes, detected inside or in close proximity to blood vessels (Fig. 8C, arrows) and in the brain parenchyma (Fig. 8C, arrowheads), compared with C57BL/6 and 5XFAD mice. Peripheral infliximab treatment of 5XFAD/Tg197 mice results in significantly decreased CD45 ${ }^{\text {high }}$ leukocytes in the cortex and leptomeninges (Fig. $8 A, B$, arrowheads), as well as decreased infiltration of $\mathrm{CD} 45^{\text {high }}$ leukocytes in the brain parenchyma (Fig. 8C). Quantitation of CD $45^{\text {high }}$ leukocytes in the cortex of the studied mouse groups using ImageJ software revealed a remarkable increase in Tg197 and 5XFAD/Tg197 mice compared with the C57BL/6 and $5 \mathrm{XFAD}$ (Fig. 8D). Notably, the presence of the 5XFAD transgene in 5XFAD/Tg197 mice results in a statistically significant $107 \%$ increase of infiltrating CD $45^{\text {high }}$ leukocytes compared with Tg197 mice (Fig. $8 D$ ). Infliximab-treated 5XFAD/Tg197 mice display significantly decreased CD $45^{\text {high }}$ leukocytes compared with 5XFAD/Tg197 mice (Fig. 8D).
B Brain 5XTg197

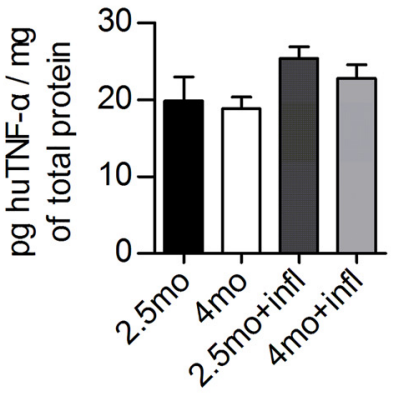

CD31

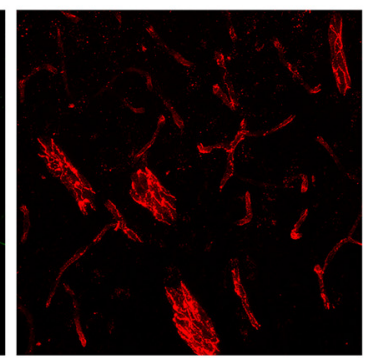

SMA

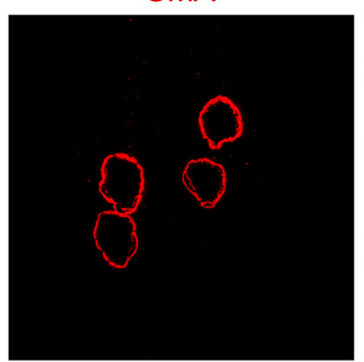

Merge
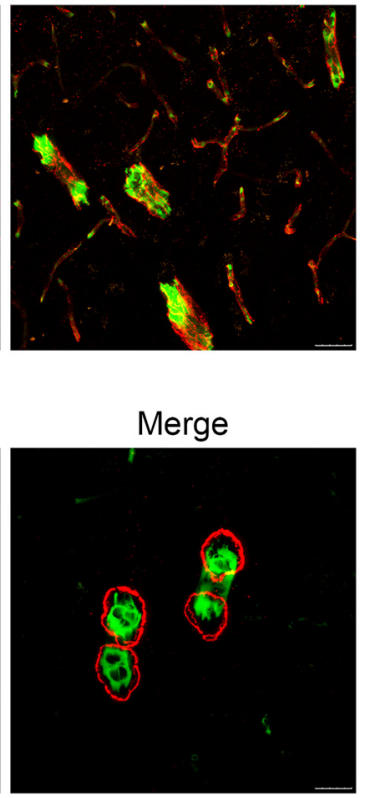

Figure 6. Infliximab reduces only peripheral and not brain huTNF- $\alpha$ levels in 5 XFAD/Tg197+ infl mice and is detectable only in the brain blood vessels and not in the parenchyma. $\boldsymbol{A}, \boldsymbol{B}$, ELISA measurement of huTNF- $\alpha$ levels in the serum $(\boldsymbol{A})$ and brain $(\boldsymbol{B})$ of 4-month-old 5XFAD/Tg197 and infliximab-treated (+ infl) 5XFAD/Tg197 mice. Infliximab-treated 5XFAD/Tg197 mice show significantly reduced serum huTNF- $\alpha(\boldsymbol{A})$, whereas their brain huTNF- $\alpha$ levels remain unaltered $(\boldsymbol{B})$. Data are mean $\pm \mathrm{SEM}$; $n=5$ per group. ${ }^{*} p<0.05$ (one-way ANOVA followed by Tukey's posthoc test). ${ }^{* *} p<0.01$ (one-way ANOVA followed by Tukey's 5XFAD/Tg197 mice using an FITC-labeled anti-hulgG antibody. Sections were double-stained for infliximab and blood vessel markers: $(C)$ CD31 and (D) $\alpha$-SMA. Immunodetection of infliximab is restricted inside the vessel lumen. Representative pictures of the cortex of 5XFAD/Tg197+infl mice are shown. Scale bars, $25 \mu \mathrm{m}$.

Overall, these results show that peripheral huTNF- $\alpha$ is able to regulate the activation and CD45 expression of microglia and the recruitment of $\mathrm{CD} 45^{\text {high }}$ leukocytes in the brain. In addition, the enhanced increase of infiltrating CD $45^{\text {high }}$ leukocytes in 5XFAD/ Tg197 mice compared with the Tg197 suggests that amyloid pathology further induces recruitment of peripheral immune cells.

5XFAD/Tg197 mice show increased Ly6C-positive monocytes and CD68-positive phagocytic macrophages/microglia in the brain, which are reduced upon peripheral huTNF- $\alpha$ inhibition by infliximab

To further elucidate the identity of peripherally derived immune cells in the brain of 5XFAD/Tg197 mice, we examined for the presence of monocytes/macrophages because these myeloid subsets have been implicated in amyloid pathology (MeyerLuehmann and Prinz, 2015). To examine whether peripheral huTNF- $\alpha$ is able to regulate the recruitment of monocytes in the 

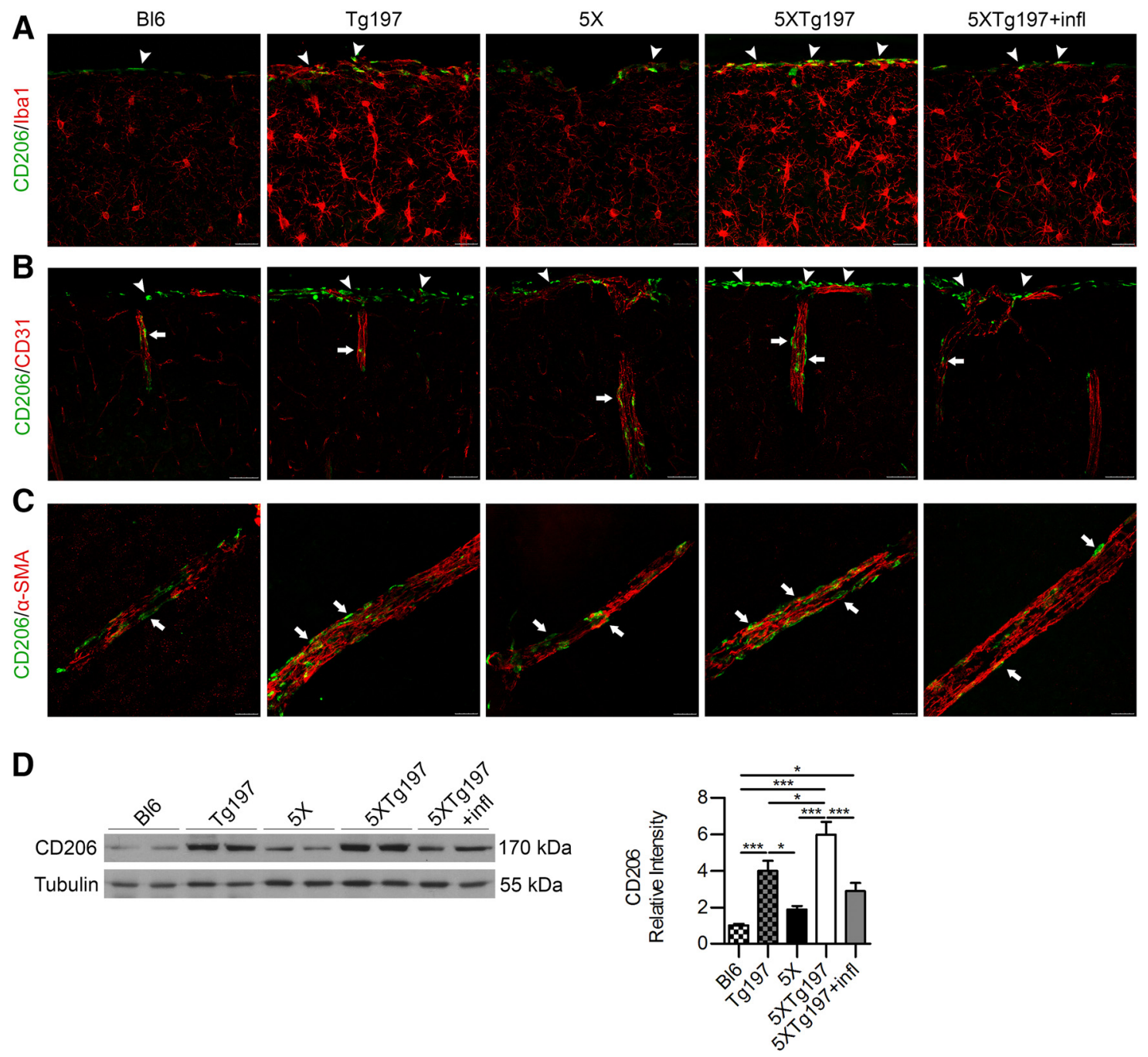

Figure 7. 5XFAD/Tg197 mice display increased CD206-positive meningeal and perivascular macrophages that are reduced upon peripheral huTNF- $\alpha$ inhibition by infliximab. Elevated CD206positive macrophages represent a phenotypic characteristic of Tg197 mice, whereas the presence of the $5 X F A D$ transgene confers an additive effect. $A-C$, Double immun ofluorescence for $C D 206 / \mathrm{lba} 1$ (A), CD206/CD31 (B), and CD206/ $\alpha$-SMA (C) in sagittal brain sections of 2.5-month-old C57BL/6, Tg197, 5XFAD, 5XFAD/Tg197, and infliximab-treated (+infl) 5XFAD/Tg197 mice. Arrowheads indicate meningeal macrophages. Arrows indicate perivascular CD206-positive macrophages. Representative pictures of the cortex and cortical vessels are shown for each group. Scale bars: $A, C, 25$ $\mu \mathrm{m} ; \boldsymbol{B}, 50 \mu \mathrm{m}$. D, Western blot analysis of CD206 brain protein levels in 2.5-month-old (57BL/6, Tg197, 5XFAD, 5XFAD/Tg197, and infliximab-treated (+infl) 5XFAD/Tg197 mice revealed an increase in Tg197 and 5XFAD/Tg197 mice compared with the C57BL/6 and 5XFAD. Notably, 5XFAD/Tg197 mice show significantly increased CD206 levels compared with the Tg197. Infliximabtreated 5XFAD/Tg197 mice display reduced CD206 levels compared with the 5XFAD/Tg197. Quantitation was performed with densitometric analysis using ImageJ software. Data are mean \pm SEM; $n=2$ mice per group; experiment repeated 3 times. ${ }^{*} p<0.05$ (one-way ANOVA followed by Tukey's post hoc test). ${ }^{* *} p<0.001$ (one-way ANOVA followed by Tukey's post hoc test).

brain, we performed immunofluorescence for the monocytic marker Ly6C in brain sections of C57BL/6, Tg197, 5XFAD, 5XFAD/Tg197, and infliximab-treated 5XFAD/Tg197 mice. Sections were also counterstained with DAPI. Confocal analysis revealed an increase of $\mathrm{Ly} 6 \mathrm{C}^{+}$patrolling monocytes along the blood vessels of Tg197 and 5XFAD/Tg197 brains compared with the C57BL/6 and 5XFAD, whereas peripheral huTNF- $\alpha$ inhibi-

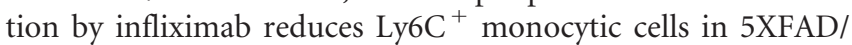
Tg197+infl mice (Fig. 9A, arrowheads). Furthermore, doublelabeling for Ly6C/Ibal showed that the robustly activated Iba1 ${ }^{+}$ microglia of Tg197 and 5XFAD/Tg197 mice is closely associated with increased Ly6C ${ }^{+}$monocytes (Fig. 9B, arrowheads), indicating that Tg197 and 5XFAD/Tg197 microglia acquire the characteristic elongated morphology likely due to their interaction with Ly6C ${ }^{+}$monocytic cells along the cerebral vessels. C57BL/6 and 5XFAD mice do not display any interaction between $\mathrm{Ibal}^{+} \mathrm{mi}^{+}$ croglia and Ly6C ${ }^{+}$monocytes (Fig. 9B). In accordance with the reduction of $\mathrm{Ly}_{6 \mathrm{C}} \mathrm{C}^{+}$monocytes, activation of microglia along the blood vessels is decreased in infliximab-treated 5XFAD/Tg197 mice (Fig. 9B). These results suggest that peripheral huTNF- $\alpha$ regulates the recruitment of blood monocytes in the brain vasculature that in turn contribute to the activation of parenchymal microglia.

The increased inflammatory cell populations observed in 5XFAD/Tg197 brains in combination with the strongly suppressed amyloid deposition suggest for the potential involvement of cell-mediated $\mathrm{A} \beta$ clearance mechanisms. Based on this hypothesis, we immunostained brain sections of C57BL/6, Tg197, 5XFAD, 5XFAD/Tg197, and infliximab-treated 5XFAD/Tg197 mice for CD68, a lysosomal marker associated with phagocytic cells (da Silva and Gordon, 1999) that is expressed by macrophages, microglia, dendritic cells, and osteoclasts (MartinezPomares et al., 1996; Greaves and Gordon, 2002) and has been recently implicated in $\mathrm{AD}$ (Matsumura et al., 2015; Minett et al., 2016). To distinguish between resident microglia and possible peripherally derived macrophages, we performed double im- 
A BI6

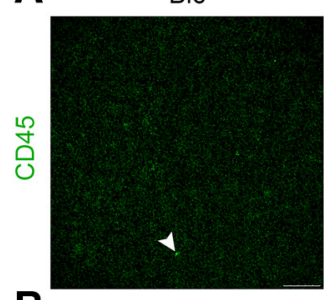

B

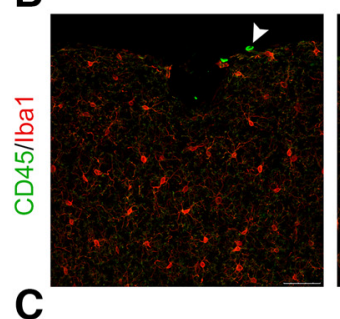

C
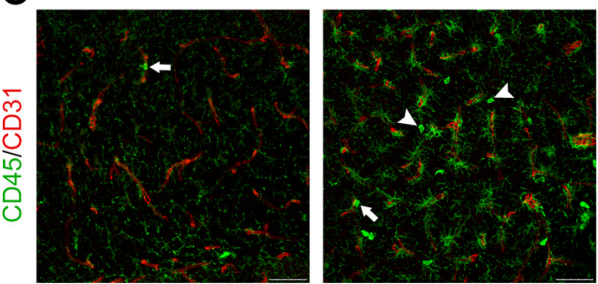

$5 X$
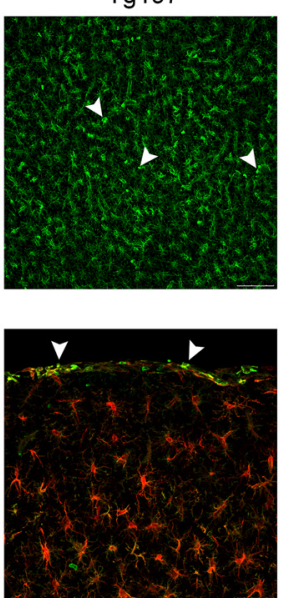
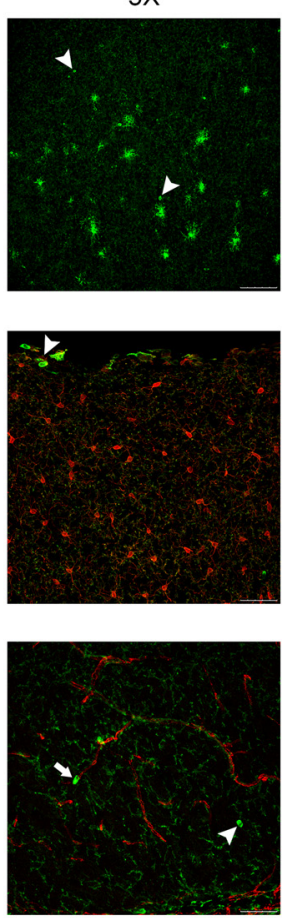

D

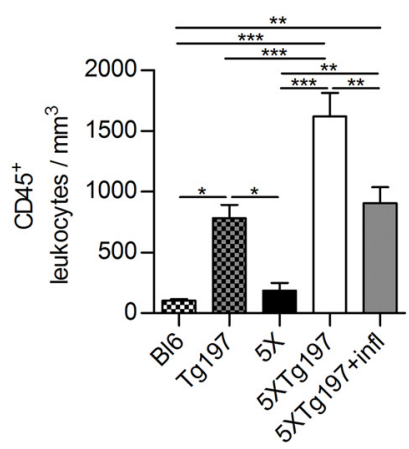

E

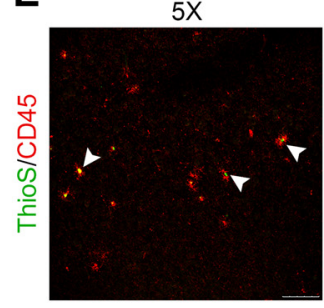

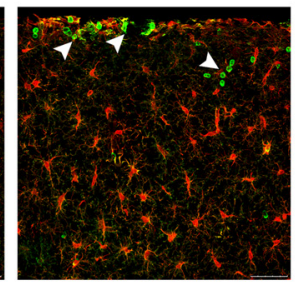
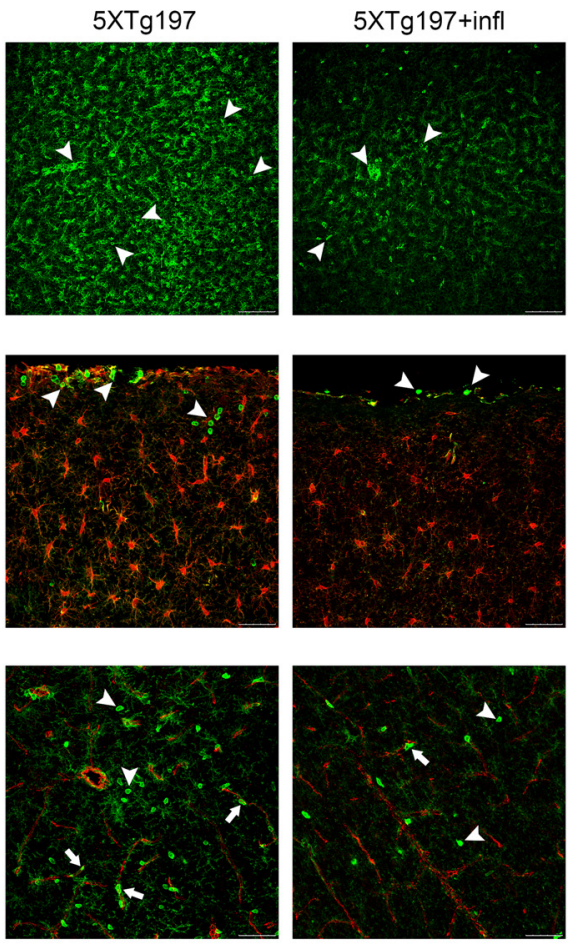

Figure 8. $5 X \mathrm{XFD} / \mathrm{Tg} 197$ brains show increased CD45 ${ }^{\text {high }}$ microglia and infiltrating leukocytes that are reduced upon peripheral huTNF- $\alpha$ inhibition by infliximab. Elevated CD45 ${ }^{\text {high }}$ leukocytes comprise a feature of Tg197 mice, whereas the presence of the 5XFAD transgene further enhances leukocyte infiltration. $\boldsymbol{A}-\boldsymbol{C}$, Immunofluorescent detection of CD45 (A) and double-labeling for CD45/lba1 (B) and CD45/CD31 (C) in sagittal brain sections of 2.5-month-old C57BL/6, Tg197, 5XFAD, 5XFAD/Tg197, and infliximab-treated (+ infl) 5XFAD/Tg197 mice. $A$, CD45 identifies both resting (CD45 ${ }^{\text {low }}$ ) and activated (CD45 high) microglia and CD45 high round-shaped leukocytes (arrowheads). B, CD45 high round-shaped leukocytes are lba1-negative. C, Arrowheads indicate CD45 ${ }^{\text {high }}$ leukocytes in the parenchyma. Arrows indicate CD45 high leukocytes in close association with blood vessels. Representative pictures of the cortex $(\boldsymbol{A}, \boldsymbol{B})$ and corpus callosum $(\boldsymbol{C})$ are shown for each group. Scale bars: $A, 100 \mu \mathrm{m} ; \boldsymbol{B}, \boldsymbol{C}, 50 \mu \mathrm{m}$. D, Quantitation of CD45 high leukocytes in the cortex of 2.5-month-old C57BL/6, Tg197, 5XFAD, 5XFAD/Tg197, and infliximab-treated ( + infl) 5XFAD/Tg197 mice revealed an increase in Tg197 and 5XFAD/Tg197 mice compared with the C57BL/6 and 5XFAD. Importantly, 5XFAD/Tg197 mice show significantly increased CD45 high leukocytes compared with the Tg197. Infliximab-treated 5XFAD/Tg197 mice display reduced number of CD45 high leukocytes compared with the 5XFAD/Tg197. Analysis was performed using ImageJ software. Data are mean $\pm \mathrm{SEM} ; n=5$ per group. ${ }^{*} p<0.05$ (one-way ANOVA followed by Tukey's post hoc test). ${ }^{* *} p<0.01$ (one-way ANOVA followed by Tukey's post hoc test). ${ }^{* * *} p<0.001$ (one-way ANOVA followed by Tukey's post hoc test). $E$, Immunofluorescent staining for CD45 and Thioflavine $S$ in sagittal brain sections of 2.5-month-old 5XFAD mice. CD45 high activated microglial cells observed in 5XFAD mice are plaque-associated. A representative picture of the cortical area is shown. Scale bar, $100 \mu \mathrm{m}$.

munofluorescence for CD68 and the recently identified microglia-specific marker TMEM119, a transmembrane protein of unknown function (Bennett et al., 2016; Satoh et al., 2016). Confocal analysis revealed a diffused pattern of robustly increased CD68 immunoreactivity in Tg197 and 5XFAD/Tg197 mice compared with the C57BL/6 and 5XFAD (Fig. 9C), suggesting for increased phagocytic activity as a result of huTNF- $\alpha$ expression. $\mathrm{CD}^{+}{ }^{+}$cells are scattered throughout the brain parenchyma in Tg197 and 5XFAD/Tg197 mice, whereas in 5XFAD mice $\mathrm{CD}^{+}{ }^{+}$cells are restricted around Thioflavine S-positive plaques (Fig. 9C). C57BL/6 brains showed minimal CD68 immunoreactivity. Peripheral infliximab treatment of 5XFAD/Tg197 mice results in significantly reduced $\mathrm{CD}^{+} 8^{+}$cells, whereas the immunoreactivity pattern remains diffused (Fig. 9C). Confocal imaging also showed extensive reduction of TMEM119 immunoreactivity in Tg197 and 5XFAD/Tg197 mice compared with C57BL/6 and 5XFAD mice (Fig. 9C). 5XFAD brains display similar TMEM119 immunoreactivity pattern to $\mathrm{C} 57 \mathrm{BL} / 6$ brains. Upon peripheral inhibition of huTNF- $\alpha$ by infliximab, TMEM119 immunoreactivity is partially restored in $5 \mathrm{XFAD} / \mathrm{Tg} 197+$ infl mice (Fig. $9 C$ ), implying that peripheral huTNF- $\alpha$ strongly affects the microglial phenotype. Additionally, both CD68 ${ }^{+}{\text {TMEM } 119^{+}}^{+}$ (Fig. 9C, arrowheads) and CD68 ${ }^{+}$TMEM119 $^{-}$(Fig. 9C, arrows) cells are detected in the brain of Tg197 and 5XFAD/Tg197 mice, whereas in the $5 \mathrm{XFAD} / \mathrm{Tg} 197+$ infl brain parenchyma we observed mostly $\mathrm{CD} 8^{+}{ }^{\mathrm{TMEM}} 119^{+}$cells. Interestingly, 5XFAD and 5XFAD/ 
A

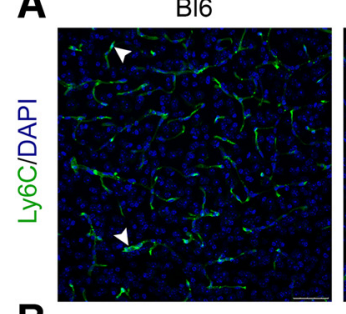

B

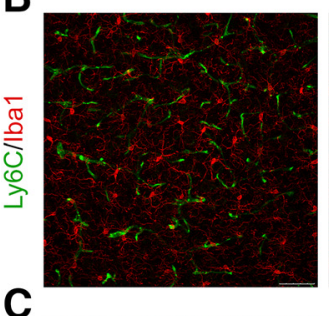

c

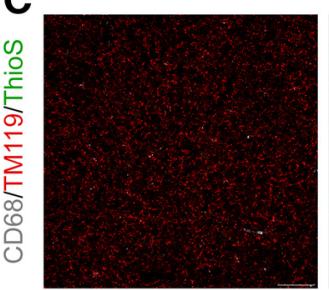

Tg197
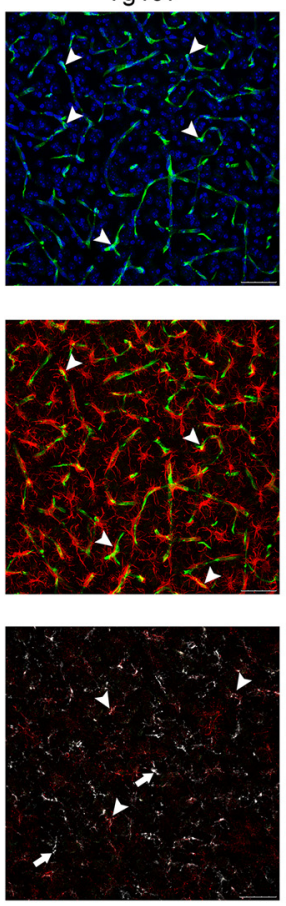

$5 X$
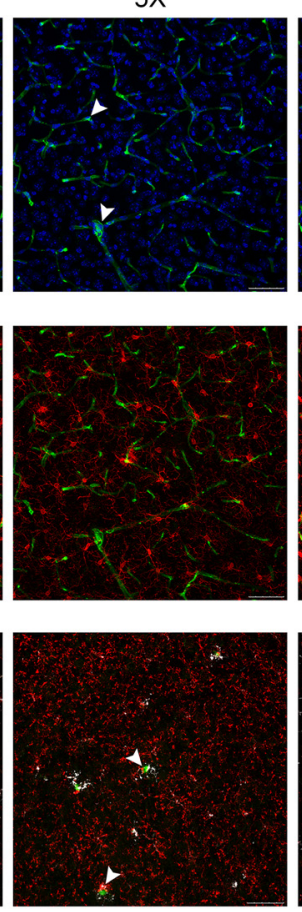

5XTg197
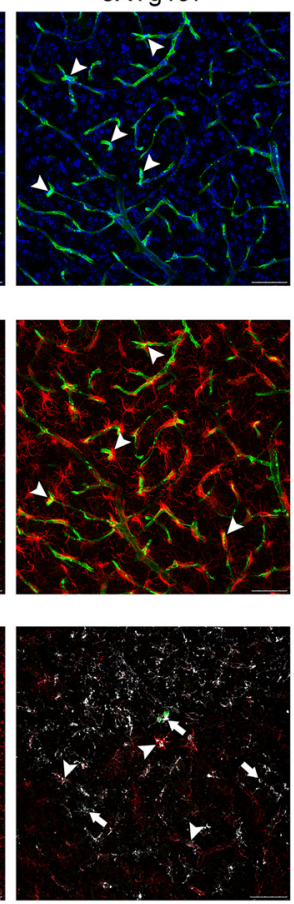

5XTg197+infl
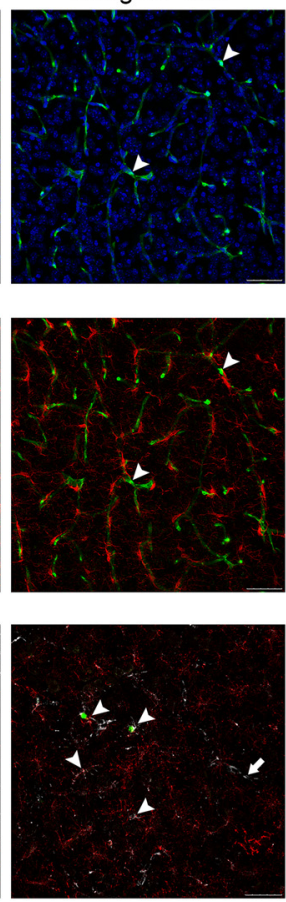

Figure 9. 5XFAD/Tg197 brains display increased Ly6C ${ }^{+}$monocytes and $\mathrm{CD} 68{ }^{+}$phagocytic macrophages/microglia that are reduced upon peripheral huTNF- $\alpha$ inhibition by infliximab. Elevated Ly6C and CD68 immunoreactivity represents a phenotypic characteristic of Tg197 mice. $A, B$, Ly6C/DAPI (A) and Ly6C/lba1 (B) fluorescent staining in sagittal brain sections of 2.5-month-old C57BL/6, Tg197, 5XFAD, 5XFAD/Tg197, and infliximab-treated (+infl) 5XFAD/Tg197 mice. Increased Ly6C ${ }^{+}$patrolling monocytes along the blood vessels can be detected in Tg197 and 5XFAD/Tg197 brains compared with the C57BL/6 and 5XFAD, whereas peripheral infliximab treatment of 5XFAD/Tg197 mice reduces Ly6C ${ }^{+}$monocytes ( $\boldsymbol{A}$, arrowheads). Double Ly6C//ba1immunostaining revealed that activated microglial cells with elongated morphology are detected in close association with $\mathrm{Ly} 6 \mathrm{C}^{+}$monocytes in the brain blood vasculature of $\mathrm{Tg} 197$ and $5 X \mathrm{XFD} / \mathrm{Tg} 197$ mice (B, arrowheads). Microglial activation along the blood vessels is decreased in infliximab-treated 5XFAD/Tg197 mice ( $\boldsymbol{B}$, arrowheads). $\boldsymbol{C}$, Immunofluorescent detection of CD68/TMEM119 in sagittal brain sections of 2.5-month-old C57BL/6, Tg197, 5XFAD, 5XFAD/Tg197, and infliximab-treated (+ infl) 5XFAD/Tg197 mice. Sections were also stained for amyloid plaques with Thioflavine S. Microglia-specific TMEM119 immunoreactivity is decreased in Tg197 and 5XFAD/Tg197 brains and partially restored upon peripheral infliximab treatment of 5XFAD/Tg197 mice, although the pattern of expression remains abnormal. Tg197 and 5XFAD/Tg197 brains show increased phagocytic CD68 ${ }^{+} \mathrm{TMEM}_{119}{ }^{+}$microglia (arrows) and CD68 ${ }^{+} \mathrm{TMEM}_{119}{ }^{-}$macrophages (arrowheads) that are significantly reduced upon peripheral infliximab treatment of 5XFAD/Tg197 mice. CD68 ${ }^{+}$TMEM119 ${ }^{-}$macrophages surrounding amyloid deposits are detected in 5XFAD/Tg197 brains compared with plaqueassociated CD68 ${ }^{+} \mathrm{TMEM}_{119}{ }^{+}$microglia in 5XFAD and infliximab-treated 5XFAD/Tg197 brains. Representative pictures of the cortex are shown for each group. Scale bars, $50 \mu \mathrm{m}$.

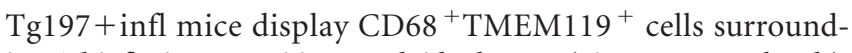
ing Thioflavine S-positive amyloid plaques (Fig. 9C, arrowheads), whereas 5XFAD/Tg197 exhibit CD68 ${ }^{+}$TMEM119 $^{-}$plaque-associated cells (Fig. 9C, arrows). These data propose that peripheral huTNF- $\alpha$ induces upregulation of phagocytic macrophages other than resident microglia that seem to contribute to the restriction of amyloid deposits in 5XFAD/Tg197 mice.

5XFAD/Tg197 mice display significant neuronal damage and synaptic loss that is markedly restored upon peripheral huTNF- $\alpha$ inhibition by infliximab

Several studies support for a concentration-dependent role of TNF- $\alpha$ in neuronal function and synaptic plasticity (for review, see Santello and Volterra, 2012). Moreover, studies during the last decade have shown that microglia constitutively contact synapses in the normal brain and affect neural networks by phagocytosis of cellular elements or by releasing various neuroactive factors, including TNF- $\alpha$, that mediate neuron-microglia crosstalk (Kettenmann et al., 2013). Taking these studies into consideration, we hypothesized that increased brain huTNF- $\alpha$ levels and/or microglial activation in Tg197 and 5XFAD/Tg197 mice could affect neuronal and synaptic integrity. To address this possibility, we performed immunofluorescence for MAP2 and synaptophysin (a presynaptic protein found in the synaptic vesicle membrane) in brain sections of C57BL/6, Tg197, 5XFAD, 5XFAD/Tg197, and infliximab-treated 5XFAD/Tg197 mice. Sub- sequent confocal analysis confirmed extensive loss of MAP2 and synaptophysin in Tg197 and 5XFAD/Tg197 mice compared with C57BL/6 and 5XFAD mice (Fig. 10A,B), indicating that disturbance of neuronal and synaptic integrity is caused by huTNF- $\alpha$ expression. Interestingly, peripheral huTNF- $\alpha$ inhibition by infliximab markedly increased MAP2 and synaptophysin immunoreactivity (Fig. 10A,B). Quantitation of dendritic MAP2 immunoreactivity and synaptophysin intensity in the cortex of the studied mouse groups using ImageJ software confirmed a significant decrease in Tg197 and 5XFAD/Tg197 mice compared with the C57BL/6 and 5XFAD (Fig. 10C,D). Importantly, the presence of the 5XFAD transgene in 5XFAD/Tg197 mice results in a statistically significant reduction of dendritic MAP2 immunoreactivity compared with Tg197 mice (Fig. 10C), whereas synaptophysin intensity showed no difference between these 2 mouse groups (Fig. 10D). The enhanced MAP2 loss observed in 5XFAD/ Tg197 brains compared with the Tg197 leads to the conclusion that the inflammatory Tg197 and amyloid 5XFAD phenotypes synergistically affect neuronal integrity. Infliximab-treated 5XFAD/Tg197 mice display significantly restored dendritic MAP2 and synaptophysin immunoreactivity close to the levels of 5XFAD mice (Fig. $10 C, D)$, suggesting that neuronal damage and synaptic degeneration in 5XFAD/Tg197 mice are mostly attributed to peripheral huTNF- $\alpha$.

The observed neuronal damage and synaptic loss in 5XFAD/ Tg197 mice could potentially result in a reduction of APP levels 
A

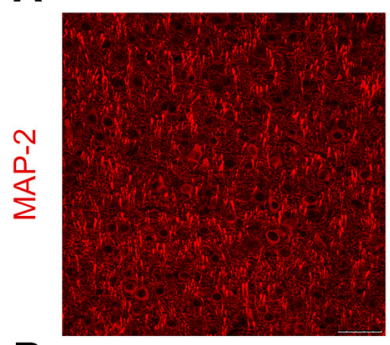

B

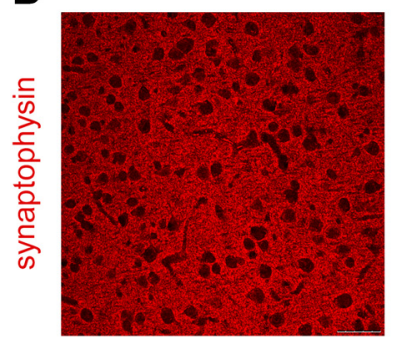

C

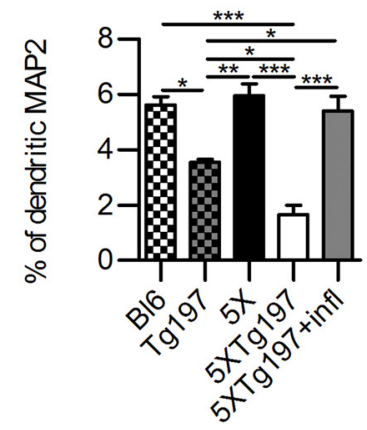

$\operatorname{Tg} 197$
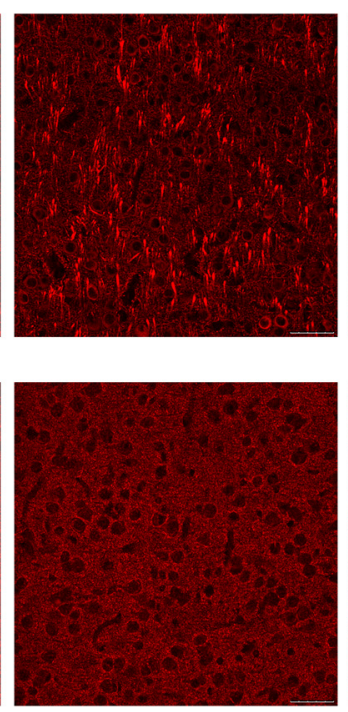

D

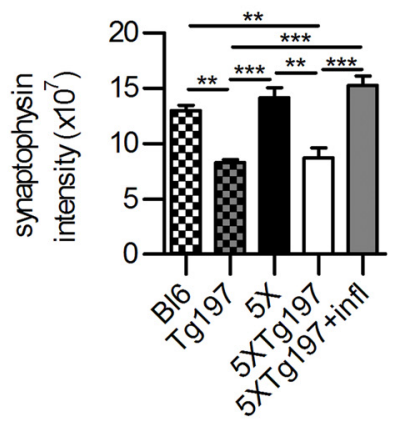

$5 X$
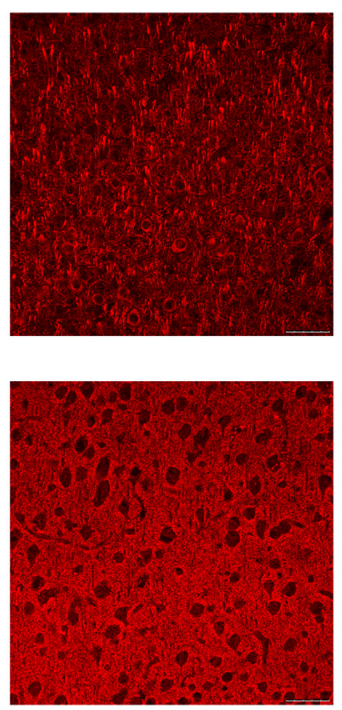

5XTg197
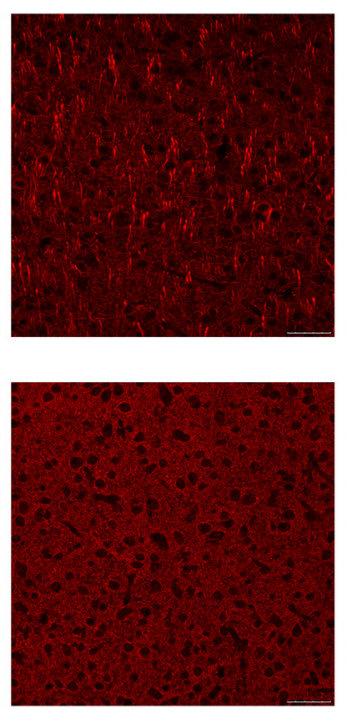

5XTg197+infl
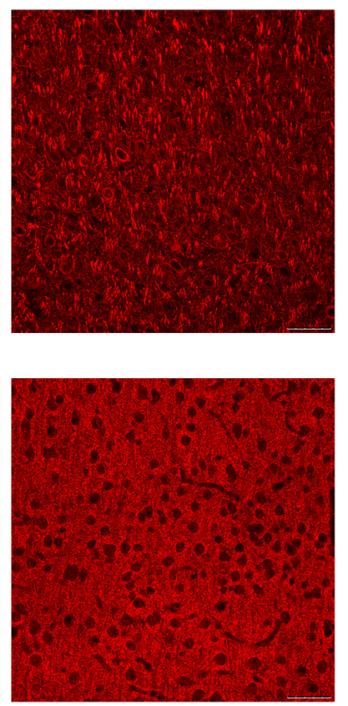

E

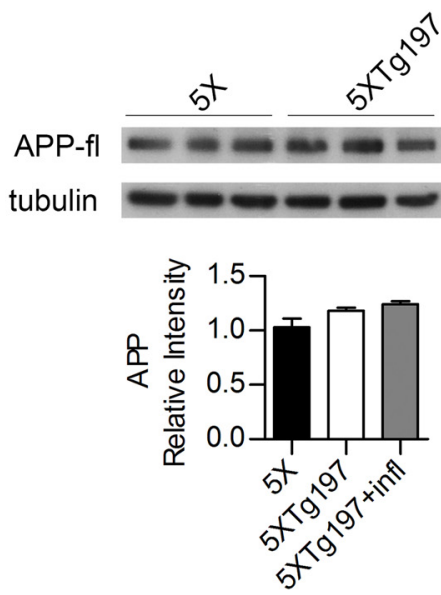

Figure 10. $5 X \mathrm{XFD} / \mathrm{Tg} 197$ mice show extensive loss of MAP2 and synaptophysin immunoreactivity that is markedly restored upon peripheral huTNF- $\alpha$ inhibition by infliximab. Reduced MAP2 and synaptophysin comprise a feature of Tg197 mice, whereas the presence of the 5 XFAD transgene further enhances MAP2 loss. $\boldsymbol{A}, \boldsymbol{B}$, Immunofluorescence for MAP2 $(\boldsymbol{A})$ and synaptophysin $(\boldsymbol{B})$ in sagittal brain sections of 2.5-month-old C57BL/6, Tg197, 5XFAD, 5XFAD/Tg197, and infliximab-treated (+infl) 5XFAD/Tg197 mice. Representative pictures of the cortex are shown for each group. Scale bars, $50 \mu \mathrm{m}$. C, D, Quantitation of dendritic MAP2 staining and synaptophysin immunoreactivity in the cortex of 2.5-month-old C57BL/6, Tg197, 5XFAD, 5XFAD/Tg197, and infliximab-treated (+infl) 5XFAD/Tg197 mice revealed a decrease in Tg197 and 5XFAD/Tg197 mice compared with the C57BL/6 and 5XFAD. Notably, 5XFAD/Tg197 mice show significantly reduced dendritic MAP2 immunoreactivity compared with the $\operatorname{Tg} 197$ (C). Infliximab-treated 5XFAD/Tg197 mice display increased dendritic MAP2 ( $($ ) and synaptophysin (D) immunoreactivity compared with the 5XFAD/ $\mathrm{Tg} 197$. Analysis was performed using ImageJ software. Data are mean \pm SEM; $n=5$ mice per group. ${ }^{*} p<0.05$ (one-way ANOVA followed by Tukey's post hoc test). ${ }^{* *} p<0.01$ (one-way ANOVA followed by Tukey's post hoc test). ${ }^{* * *} p<0.001$ (one-way ANOVA followed by Tukey's post hoc test). E, Western blot analysis of full-length APP brain protein levels in 2.5-month-old 5XFAD, 5XFAD/Tg197, and infliximab-treated (+infl) 5XFAD/Tg197 mice showed no difference among the three analyzed groups. Quantitation was performed with densitometric analysis using Image J software. Data are mean \pm SEM; $n=3$ mice per group; experiment repeated 2 times using different samples. For statistical analyses, one-way ANOVA followed by Tukey's post hoc test was used.

and accordingly in decreased $\mathrm{A} \beta$ production and amyloid plaque formation. To test this hypothesis, we evaluated the levels of fulllength APP in total brain protein extracts from 5XFAD, 5XFAD/ Tg197, and infliximab-treated 5XFAD/Tg197 mice by Western blotting. Subsequent analysis showed no significant difference of full-length APP protein levels among the 3 mouse groups (Fig. 10E), suggesting that the remarkable reduction of amyloid burden in 5XFAD/Tg197 mice is not caused by decreased production of APP.

\section{Discussion}

The aim of our study was to elucidate the role of TNF- $\alpha$ as a mediator of systemic inflammatory arthritis in the pathogenic process of AD. We report that 5XFAD/Tg197 AD/TNF transgenic mice, which express huTNF- $\alpha$ both in the periphery and the brain and develop arthritis, show significantly decreased amyloid deposition, robust glial activation, and compromised neuronal integrity. Further analysis revealed a strong upregulation of bloodderived immune cell populations in the 5XFAD/Tg197 brain. To evaluate whether the 5XFAD/Tg197 brain phenotype is attributed to peripheral or brain huTNF- $\alpha$, we treated 5XFAD/Tg197 mice peripherally with infliximab anti-huTNF-specific antibody that inhibits arthritis and does not penetrate the BBB. Infliximab inhibits only peripheral huTNF- $\alpha$ and attenuates neuronal damage but significantly enhances $\mathrm{A} \beta$ deposition in 5XFAD/Tg197+infl mice. Infliximab treatment also reduces recruitment of bloodderived mononuclear cells in the brain and suppresses glial activation. Our findings demonstrate that the brain phenotype of $5 \mathrm{XFAD} / \mathrm{Tg} 197$ mice is substantially regulated by peripheral huTNF- $\alpha$.

Although neuroinflammation has been established as a prominent feature in AD pathogenesis (Heppner et al., 2015), evidence 
suggests that systemic inflammation associated with infection, injury, or obesity also contributes to $\mathrm{AD}$ progression and local brain inflammatory response (Perry, 2004; O’Banion, 2014; Calsolaro and Edison, 2016). Systemic inflammation also occurs in RA, a chronic autoimmune disease driven by TNF- $\alpha$ (Feldmann, 2002). RA patients receiving anti-TNF- $\alpha$ drugs (infliximab, etanercept, adalimumab) show reduced risk of developing AD (Chou et al., 2016), raising questions about the role of RA and/or antiTNF- $\alpha$ therapy in AD. Collagen-induced arthritis in the APP/PS1 mouse model results in reduced amyloid pathology and activated microglia (Park et al., 2011). On the contrary, exacerbated amyloid deposition was observed in APP/PS1 mice with IL- $1 \beta$ induced osteoarthritis even though microglia and astrocytes also show increased activation (Kyrkanides et al., 2011). Considering that TNF- $\alpha$ is a key mediator of RA pathogenesis that has been implicated in AD (Montgomery and Bowers, 2012), we combined Tg197 and 5XFAD mouse models to investigate the impact of huTNF-induced arthritis in amyloid pathology. huTNF- $\alpha$ expression in 5XFAD/Tg197 AD/TNF transgenic mice results in reduced amyloid deposition and $A \beta$ levels and robust microglial and astrocytic activation, in agreement with the study by Park et al. (2011). To determine whether peripheral or brain huTNF- $\alpha$ independently or synergistically contributes to the activation of glial cells and the reduction of amyloid pathology, we treated 5XFAD/Tg197 mice systemically with infliximab anti-huTNFspecific antibody to block peripheral huTNF- $\alpha$. Peripheral infliximab treatment significantly restores amyloid deposition by the age of 4 months, attenuates glial activation, and reduces circulating huTNF- $\alpha$ without affecting brain huTNF- $\alpha$, suggesting that the observed alterations in the 5XFAD/Tg197 brain are mediated primarily by peripheral huTNF- $\alpha$. huTNF-induced glial activation is already observed by the age of 1 month in Tg197 mice, before starting infliximab treatment, suggesting that peripheral huTNF- $\alpha$ inhibition in 5XFAD/Tg197+infl mice suppresses rather than prevents glial activation.

To elucidate the mechanisms by which peripheral huTNF- $\alpha$ regulates the glial response and amyloid phenotype in 5XFAD/ Tg197 mice, we expanded our analysis to blood-derived immune cell populations, as TNF-dependent recruitment of blood-derived mononuclear cells in the brain has been observed during peripheral inflammation. In mice with endotoxemia, peripheral CD $45^{+}$ monocytes are attracted to the brain vasculature and give rise to perivascular macrophages in response to TNF- $\alpha$, IL- $1 \beta$, and angiopoietin-2 (Audoy-Rémus et al., 2008). Moreover, peripheral TNF- $\alpha$ signaling appears to be required for microglial activation and subsequent recruitment of $\mathrm{Ly}_{6 \mathrm{C}}{ }^{+}$and $\mathrm{CD} 11 \mathrm{~b}^{+} \mathrm{CD} 45^{\text {high }}$ monocytes into the brain in a mouse model of peripheral hepatic inflammation (D'Mello et al., 2009). Evidence suggests that recruitment of peripheral mononuclear cells also occurs in the $\mathrm{AD}$ mouse brain, playing a major role in restricting amyloid plaques (Simard et al., 2006). Genetic ablation of the chemokine receptor CCR2 in the Tg2576 AD mouse model resulted in decreased brain infiltration of blood-derived mononuclear cells and increased amyloid deposition (El Khoury et al., 2007), whereas a subsequent study concluded that perivascular macrophages are able to modulate $\mathrm{A} \beta$ deposition in a CCR2-dependent manner (Mildner et al., 2011). Perivascular macrophages have been also involved in $\mathrm{A} \beta$ clearance in a mouse model of cerebral amyloid angiopathy (Hawkes and McLaurin, 2009). Our present study revealed robust infiltration of CD45 ${ }^{\text {high }}$ leukocytes and significant increase of CD206positive meningeal/perivascular macrophages in the $\operatorname{Tg} 197$ and 5XFAD/Tg197 mouse brain compared with the C57BL/6 and 5XFAD. Similarly to 5XFAD/Tg197, an increase of CD206- positive macrophages in leptomeningeal and perivascular regions has been reported in $\mathrm{AD}$ mice with collagen-induced arthritis (Park et al., 2011), indicating that inflammatory arthritis modulates this cell population in the brain. In infliximab-treated 5XFAD/Tg197 mice, peripheral huTNF- $\alpha$ inhibition substantially reduced infiltrating leukocytes and meningeal/perivascular macrophages, implying that peripheral huTNF- $\alpha$ regulates their recruitment in the brain. Interestingly, 5XFAD/Tg197 mice showed a further enhancement of CD45 high leukocytes and CD206-positive macrophages compared with Tg197, suggesting that these immune cell populations are actively involved in the modulation of $\mathrm{A} \beta$ pathology. Furthermore, we detected increased Ly6C ${ }^{+}$monocytes patrolling the blood vessels of Tg197 and 5XFAD/Tg197 brains, whereas peripheral huTNF- $\alpha$ inhibition reduces $\mathrm{Ly}_{6 \mathrm{C}}{ }^{+}$monocytic cells in infliximab-treated 5XFAD/ Tg197 brains, indicating that peripheral huTNF- $\alpha$ regulates the recruitment of blood monocytes in the cerebral vasculature. Interestingly, Ly6C ${ }^{+}$monocytes appear to contribute to the activation and morphological changes of parenchymal microglia, as activated microglia are observed in close association with increased Ly6C ${ }^{+}$monocytes in Tg197 and 5XFAD/Tg197 cerebral blood vessels, an effect that is suppressed upon peripheral huTNF- $\alpha$ inhibition by infliximab.

CD68 is a lysosomal protein indicative of phagocytic macrophages/microglia and has been associated with $\mathrm{AD}$ in patients and animal models (Matsumura et al., 2015; Minett et al., 2016). TMEM119 is a recently identified microglia-specific marker that can be used to distinguish resident microglia from blood-derived macrophages in the brain (Bennett et al., 2016; Satoh et al., 2016). Analysis of CD68/TMEM119 immunostaining in Tg197 and 5XFAD/Tg197 brains revealed a strong increase of CD68 ${ }^{+} \mathrm{TMEM} 19^{-}$ macrophages and $\mathrm{CD} 68^{+} \mathrm{TMEM} 19^{+}$microglia, which are significantly reduced upon peripheral huTNF- $\alpha$ inhibition in infliximab-treated 5XFAD/Tg197 mice, suggesting that peripheral huTNF- $\alpha$ regulates blood-derived phagocytic macrophages as well as phagocytic microglia in the brain. The presence of

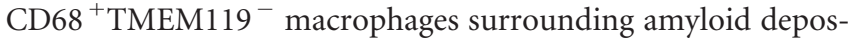
its in 5XFAD/Tg197 brains compared with plaque-associated $\mathrm{CD} 8^{+} \mathrm{TMEM} 19^{+}$microglia in 5XFAD and infliximab-treated 5XFAD/Tg197 brains suggests that blood-derived phagocytic macrophages other than resident microglia are significantly involved in the restriction of amyloid deposits in 5XFAD/Tg197 brains. Notably, the differential TMEM119 pattern observed in Tg197 and 5XFAD/Tg197 brains, which is partially reversed upon infliximab treatment, is indicative of a huTNF-induced modification of the microglial phenotype, although we cannot explain at this point its significance for microglial function as TMEM119 role remains unknown.

Several lines of evidence have suggested that TNF- $\alpha$ regulates neuronal and synaptic function both in the normal and diseased brain (Santello and Volterra, 2012). Recently, it was also shown that peripheral TNF- $\alpha$ impacts synaptic stability (Yang et al., 2013). Interestingly, neuron-specific TNF- $\alpha$ expression in AD mice results in neuronal death and extensive microglial activation (Janelsins et al., 2008), whereas in vitro data support that TNFinduced neuronal loss is mediated by microglial phagocytosis (Neniskyte et al., 2014). Furthermore, microglia have been shown to mediate synaptic loss in AD mice (Hong et al., 2016). These studies suggest microglia as a significant modulator of neuronal and synaptic integrity. Here we show that Tg197 and 5XFAD/Tg197 mice display intense MAP2 and synaptophysin reduction combined with robust microglial activation, phenotypes that are significantly reversed upon peripheral huTNF- $\alpha$ 
inhibition, although infliximab does not affect brain huTNF- $\alpha$ levels. Our findings suggest that peripheral huTNF-induced neuronal and synaptic alterations are more likely a result of microglial activation rather than a direct effect of huTNF- $\alpha$ on neurons. These neuronal alterations do not affect APP protein levels; thus, they do not contribute to the changes in amyloid deposition. Importantly, 5XFAD/Tg197 mice display enhanced MAP2 loss compared with the Tg197, suggesting for a synergistic effect of huTNF-induced inflammation and $\mathrm{A} \beta$ production on neuronal damage. This could be explained by the rapid accumulation of intraneuronal $\mathrm{A} \beta_{42}$ starting at 1.5 months of age in 5XFAD mice (Oakley et al., 2006), considering that intraneuronal $\mathrm{A} \beta_{42}$ correlates with MAP2 reduction in another AD model (Takahashi et al., 2013).

This is the first study examining the effect of peripheral TNF- $\alpha$ as a mediator of systemic inflammatory arthritis on the amyloid pathology of AD mice, by using an anti-TNF- $\alpha$ drug that has been proved effective in RA therapy and does not cross the BBB. Our findings support an unexpected role for peripheral TNF- $\alpha$ in modulating amyloid pathology and neuronal integrity by regulating the cerebral inflammatory milieu. We propose enhanced $\mathrm{A} \beta$ clearance by blood-derived cell populations and activated microglia as the underlying mechanism that mediates the substantial reduction of amyloid deposition in 5XFAD/Tg197 mice. Importantly, our study provides new insights into the role of TNF- $\alpha$ in AD as additionally to its local actions in the AD brain, TNF- $\alpha$ also indirectly impacts the progression of amyloid pathology and neuronal damage as a regulator of peripheral inflammation. Finally, it suggests that future therapeutic approaches targeting TNF- $\alpha$ in AD should involve peripheral TNF- $\alpha$ and that the potential effects of peripheral TNF- $\alpha$ modulation in the brain should be taken into consideration in the treatment of RA patients with anti-TNF- $\alpha$ drugs.

\section{References}

Assas BM, Levison SE, Little M, England H, Battrick L, Bagnall J, McLaughlin JT, Paszek P, Else KJ, Pennock JL (2017) Anti-inflammatory effects of infliximab in mice are independent of tumour necrosis factor alpha neutralization. Clin Exp Immunol 187:225-233. CrossRef Medline

Audoy-Rémus J, Richard JF, Soulet D, Zhou H, Kubes P, Vallières L (2008) Rod-shaped monocytes patrol the brain vasculature and give rise to perivascular macrophages under the influence of proinflammatory cytokines and angiopoietin-2. J Neurosci 28:10187-10199. CrossRef Medline

Bennett ML, Bennett FC, Liddelow SA, Ajami B, Zamanian JL, Fernhoff NB, Mulinyawe SB, Bohlen CJ, Adil A, Tucker A, Weissman IL, Chang EF, Li G, Grant GA, Hayden Gephart MG, Barres BA (2016) New tools for studying microglia in the mouse and human CNS. Proc Natl Acad Sci U S A 113:E1738-E1746. CrossRef Medline

Blandizzi C, Gionchetti P, Armuzzi A, Caporali R, Chimenti S, Cimaz R, Cimino L, Lapadula G, Lionetti P, Marchesoni A, Marcellusi A, Mennini FS, Salvarani C, Girolomoni G (2014) The role of tumour necrosis factor in the pathogenesis of immune-mediated diseases. Int J Immunopathol Pharmacol 27:1-10. CrossRef Medline

Calsolaro V, Edison P (2016) Neuroinflammation in Alzheimer's disease: current evidence and future directions. Alzheimers Dement 12:719-732. CrossRef Medline

Cameron B, Landreth GE (2010) Inflammation, microglia, and Alzheimer's disease. Neurobiol Dis 37:503-509. CrossRef Medline

Chakrabarty P, Herring A, Ceballos-Diaz C, Das P, Golde TE (2011) Hippocampal expression of murine TNFalpha results in attenuation of amyloid deposition in vivo. Mol Neurodegener 6:16. CrossRef Medline

Chou RC, Kane M, Ghimire S, Gautam S, Gui J (2016) Treatment for rheumatoid arthritis and risk of Alzheimer's disease: a nested case-control analysis. CNS Drugs 30:1111-1120. CrossRef Medline

Choy EH, Panayi GS (2001) Cytokine pathways and joint inflammation in rheumatoid arthritis. N Engl J Med 344:907-916. CrossRef Medline

da Silva RP, Gordon S (1999) Phagocytosis stimulates alternative glycosyla- tion of macrosialin (mouse CD68), a macrophage-specific endosomal protein. Biochem J 338:687-694. CrossRef Medline

Dickson DW (1997) The pathogenesis of senile plaques. J Neuropathol Exp Neurol 56:321-339. CrossRef Medline

D'Mello C, Le T, Swain MG (2009) Cerebral microglia recruit monocytes into the brain in response to tumor necrosis factor $\alpha$ signaling during peripheral organ inflammation. J Neurosci 29:2089-2102. CrossRef Medline

El Khoury J, Toft M, Hickman SE, Means TK, Terada K, Geula C, Luster AD (2007) Ccr2 deficiency impairs microglial accumulation and accelerates progression of Alzheimer-like disease. Nat Med 13:432-438. CrossRef Medline

Etminan M, Gill S, Samii A (2003) Effect of non-steroidal anti-inflammatory drugs on risk of Alzheimer's disease: systematic review and meta-analysis of observational studies. Br Med J 327:128. CrossRef Medline

Feldmann M (2002) Development of anti-TNF therapy for rheumatoid arthritis. Nat Rev Immunol 2:364-371. CrossRef Medline

Fillit H, Ding WH, Buee L, Kalman J, Altstiel L, Lawlor B, Wolf-Klein G (1991) Elevated circulating tumor necrosis factor levels in Alzheimer's disease. Neurosci Lett 129:318-320. CrossRef Medline

Gabbita SP, Johnson MF, Kobritz N, Eslami P, Poteshkina A, Varadarajan S, Turman J, Zemlan F, Harris-White ME (2015) Oral TNF $\alpha$ modulation alters neutrophil infiltration, improves cognition and diminishes tau and amyloid pathology in the 3xTgAD mouse model. PLoS One 10:e0137305. CrossRef Medline

Galimberti D, Fenoglio C, Scarpini E (2008) Inflammation in neurodegenerative disorders: friend or foe? Curr Aging Sci 1:30-41. CrossRef Medline

Greaves DR, Gordon S (2002) Macrophage-specific gene expression: current paradigms and future challenges. Int J Hematol 76:6-15. CrossRef Medline

Hawkes CA, McLaurin J (2009) Selective targeting of perivascular macrophages for clearance of beta-amyloid in cerebral amyloid angiopathy. Proc Natl Acad Sci U S A 106:1261-1266. CrossRef Medline

He P, Zhong Z, Lindholm K, Berning L, Lee W, Lemere C, Staufenbiel M, Li R, Shen Y (2007) Deletion of tumor necrosis factor death receptor inhibits amyloid beta generation and prevents learning and memory deficits in Alzheimer's mice. J Cell Biol 178:829-841. CrossRef Medline

Heneka MT, Carson MJ, El Khoury J, Landreth GE, Brosseron F, Feinstein DL, Jacobs AH, Wyss-Coray T, Vitorica J, Ransohoff RM, Herrup K, Frautschy SA, Finsen B, Brown GC, Verkhratsky A, Yamanaka K, Koistinaho J, Latz E, Halle A, Petzold GC, et al.(2015) Neuroinflammation in Alzheimer's disease. Lancet Neurol 14:388-405. CrossRef Medline

Heppner FL, Ransohoff RM, Becher B (2015) Immune attack: the role of inflammation in Alzheimer disease. Nat Rev Neurosci 16:358-372. CrossRef Medline

Hong S, Beja-Glasser VF, Nfonoyim BM, Frouin A, Li S, Ramakrishnan S, Merry KM, Shi Q, Rosenthal A, Barres BA, Lemere CA, Selkoe DJ, Stevens B (2016) Complement and microglia mediate early synapse loss in Alzheimer mouse models. Science 352:712-716. CrossRef Medline

Irani Y, Scotney P, Nash A, Williams KA (2016) Species cross-reactivity of antibodies used to treat ophthalmic conditions. Invest Ophthalmol Vis Sci 57:586-591. CrossRef Medline

Janelsins MC, Mastrangelo MA, Oddo S, LaFerla FM, Federoff HJ, Bowers WJ (2005) Early correlation of microglial activation with enhanced tumor necrosis factor-alpha and monocyte chemoattractant protein-1 expression specifically within the entorhinal cortex of triple transgenic Alzheimer's disease mice. J Neuroinflammation 2:23. CrossRef Medline

Janelsins MC, Mastrangelo MA, Park KM, Sudol KL, Narrow WC, Oddo S, LaFerla FM, Callahan LM, Federoff HJ, Bowers WJ (2008) Chronic neuron-specific tumor necrosis factor-alpha expression enhances the local inflammatory environment ultimately leading to neuronal death in 3xTg-AD mice. Am J Pathol 173:1768-1782. CrossRef Medline

Keffer J, Probert L, Cazlaris H, Georgopoulos S, Kaslaris E, Kioussis D, Kollias G (1991) Transgenic mice expressing human tumour necrosis factor: a predictive genetic model of arthritis. EMBO J 10:4025-4031. Medline

Kettenmann H, Kirchhoff F, Verkhratsky A (2013) Microglia: new roles for the synaptic stripper. Neuron 77:10-18. CrossRef Medline

Kyrkanides S, Tallents RH, Miller JN, Olschowka ME, Johnson R, Yang M, Olschowka JA, Brouxhon SM, O'Banion MK (2011) Osteoarthritis accelerates and exacerbates Alzheimer's disease pathology in mice. J Neuroinflammation 8:112. CrossRef Medline

Lai AY, McLaurin J (2012) Clearance of amyloid-beta peptides by microglia 
and macrophages: the issue of what, when and where. Future Neurol 7:165-176. CrossRef Medline

Lee CY, Landreth GE (2010) The role of microglia in amyloid clearance from the AD brain. J Neural Transm (Vienna) 117:949-960. CrossRef Medline

Martinez-Pomares L, Platt N, McKnight AJ, da Silva RP, Gordon S (1996) Macrophage membrane molecules: markers of tissue differentiation and heterogeneity. Immunobiology 195:407-416. CrossRef Medline

Masliah E, Mallory M, Hansen L, Alford M, Albright T, Terry R, Shapiro P, Sundsmo M, Saitoh T (1991) Immunoreactivity of CD45, a protein phosphotyrosine phosphatase, in Alzheimer's disease. Acta Neuropathol 83:12-20. CrossRef Medline

Matsumura A, Suzuki S, Iwahara N, Hisahara S, Kawamata J, Suzuki H, Yamauchi A, Takata K, Kitamura Y, Shimohama S (2015) Temporal changes of CD68 and alpha7 nicotinic acetylcholine receptor expression in microglia in Alzheimer's disease-like mouse models. J Alzheimers Dis 44:409-423. CrossRef Medline

McAlpine FE, Lee JK, Harms AS, Ruhn KA, Blurton-Jones M, Hong J, Das P, Golde TE, LaFerla FM, Oddo S, Blesch A, Tansey MG (2009) Inhibition of soluble TNF signaling in a mouse model of Alzheimer's disease prevents pre-plaque amyloid-associated neuropathology. Neurobiol Dis 34: 163-177. CrossRef Medline

McGeer PL, Schulzer M, McGeer EG (1996) Arthritis and anti-inflammatory agents as possible protective factors for Alzheimer's disease: a review of 17 epidemiologic studies. Neurology 47:425-432. CrossRef Medline

Meyer-Luehmann M, Prinz M (2015) Myeloid cells in Alzheimer's disease: culprits, victims or innocent bystanders? Trends Neurosci 38:659-668. CrossRef Medline

Mildner A, Schlevogt B, Kierdorf K, Böttcher C, Erny D, Kummer MP, Quinn M, Brück W, Bechmann I, Heneka MT, Priller J, Prinz M (2011) Distinct and non-redundant roles of microglia and myeloid subsets in mouse models of Alzheimer's disease. J Neurosci 31:11159-11171. CrossRef Medline

Minett T, Classey J, Matthews FE, Fahrenhold M, Taga M, Brayne C, Ince PG, Nicoll JA, Boche D (2016) Microglial immunophenotype in dementia with Alzheimer's pathology. J Neuroinflammation 13:135. CrossRef Medline

Montgomery SL, Bowers WJ (2012) Tumor necrosis factor-alpha and the roles it plays in homeostatic and degenerative processes within the central nervous system. J Neuroimmune Pharmacol 7:42-59. CrossRef Medline

Neniskyte U, Vilalta A, Brown GC (2014) Tumour necrosis factor alphainduced neuronal loss is mediated by microglial phagocytosis. FEBS Lett 588:2952-2956. CrossRef Medline

Oakley H, Cole SL, Logan S, Maus E, Shao P, Craft J, Guillozet-Bongaarts A, Ohno M, Disterhoft J, Van Eldik L, Berry R, Vassar R (2006) Intraneuronal beta-amyloid aggregates, neurodegeneration, and neuron loss in transgenic mice with five familial Alzheimer's disease mutations: potential factors in amyloid plaque formation. J Neurosci 26:10129-10140. CrossRef Medline

O’Banion MK (2014) Does peripheral inflammation contribute to Alzheimer disease? Evidence from animal models. Neurology 83:480-481. CrossRef Medline

Paganelli R, Di Iorio A, Patricelli L, Ripani F, Sparvieri E, Faricelli R, Iarlori C, Porreca E, Di Gioacchino M, Abate G (2002) Proinflammatory cytokines in sera of elderly patients with dementia: levels in vascular injury are higher than those of mild-moderate Alzheimer's disease patients. Exp Gerontol 37:257-263. CrossRef Medline

Park SM, Shin JH, Moon GJ, Cho SI, Lee YB, Gwag BJ (2011) Effects of collagen-induced rheumatoid arthritis on amyloidosis and microvascular pathology in APP/PS1 mice. BMC Neurosci 12:106. CrossRef Medline

Perini G, Della-Bianca V, Politi V, Della Valle G, Dal-Pra I, Rossi F, Armato U (2002) Role of $\mathrm{p} 75$ neurotrophin receptor in the neurotoxicity by betaamyloid peptides and synergistic effect of inflammatory cytokines. J Exp Med 195:907-918. CrossRef Medline

Perry VH (2004) The influence of systemic inflammation on inflammation in the brain: implications for chronic neurodegenerative disease. Brain Behav Immun 18:407-413. CrossRef Medline
Santello M, Volterra A (2012) TNFalpha in synaptic function: switching gears. Trends Neurosci 35:638-647. CrossRef Medline

Satoh J, Kino Y, Asahina N, Takitani M, Miyoshi J, Ishida T, Saito Y (2016) TMEM119 marks a subset of microglia in the human brain. Neuropathology 36:39-49. CrossRef Medline

Schottelius AJ, Moldawer LL, Dinarello CA, Asadullah K, Sterry W, Edwards CK 3rd (2004) Biology of tumor necrosis factor-alpha: implications for psoriasis. Exp Dermatol 13:193-222. CrossRef Medline

Selkoe D, Mandelkow E, Holtzman D (2012) Deciphering Alzheimer disease. Cold Spring Harb Perspect Med 2:a011460. CrossRef Medline

Sesele K, Thanopoulou K, Paouri E, Tsefou E, Klinakis A, Georgopoulos S (2013) Conditional inactivation of nicastrin restricts amyloid deposition in an Alzheimer's disease mouse model. Aging Cell 12:1032-1040. CrossRef Medline

Shealy DJ, Wooley PH, Emmell E, Volk A, Rosenberg A, Treacy G, Wagner CL, Mayton L, Griswold DE, Song XY (2002) Anti-TNF-alpha antibody allows healing of joint damage in polyarthritic transgenic mice. Arthritis Res 4:R7. CrossRef Medline

Shi JQ, Wang BR, Jiang WW, Chen J, Zhu YW, Zhong LL, Zhang YD, Xu J (2011a) Cognitive improvement with intrathecal administration of infliximab in a woman with Alzheimer's disease. J Am Geriatr Soc 59:11421144. CrossRef Medline

Shi JQ, Shen W, Chen J, Wang BR, Zhong LL, Zhu YW, Zhu HQ, Zhang QQ, Zhang YD, Xu J (2011b) Anti-TNF-alpha reduces amyloid plaques and tau phosphorylation and induces CD11c-positive dendritic-like cell in the APP/PS1 transgenic mouse brains. Brain Res 1368:239-247. CrossRef Medline

Simard AR, Soulet D, Gowing G, Julien JP, Rivest S (2006) Bone marrowderived microglia play a critical role in restricting senile plaque formation in Alzheimer's disease. Neuron 49:489-502. CrossRef Medline

Takahashi RH, Capetillo-Zarate E, Lin MT, Milner TA, Gouras GK (2013) Accumulation of intraneuronal beta-amyloid 42 peptides is associated with early changes in microtubule-associated protein 2 in neurites and synapses. PLoS One 8:e51965. CrossRef Medline

Takeuchi H, Jin S, Wang J, Zhang G, Kawanokuchi J, Kuno R, Sonobe Y, Mizuno T, Suzumura A (2006) Tumor necrosis factor-alpha induces neurotoxicity via glutamate release from hemichannels of activated microglia in an autocrine manner. J Biol Chem 281:21362-21368. CrossRef Medline

Taylor PC, Feldmann M (2009) Anti-TNF biologic agents: still the therapy of choice for rheumatoid arthritis. Nat Rev Rheumatol 5:578-582. CrossRef Medline

Tobinick E (2009) Tumour necrosis factor modulation for treatment of Alzheimer's disease: rationale and current evidence. CNS Drugs 23:713-725. CrossRef Medline

Tobinick EL, Gross H (2008) Rapid cognitive improvement in Alzheimer's disease following perispinal etanercept administration. J Neuroinflammation 5:2. CrossRef Medline

Tweedie D, Ferguson RA, Fishman K, Frankola KA, Van Praag H, Holloway HW, Luo W, Li Y, Caracciolo L, Russo I, Barlati S, Ray B, Lahiri DK, Bosetti F, Greig NH, Rosi S (2012) Tumor necrosis factor-alpha synthesis inhibitor 3,6' -dithiothalidomide attenuates markers of inflammation, Alzheimer pathology and behavioral deficits in animal models of neuroinflammation and Alzheimer's disease. J Neuroinflammation 9:106. CrossRef Medline

Van Deventer SJ (1997) Tumour necrosis factor and Crohn's disease. Gut 40:443-448. CrossRef Medline

Wyss-Coray T, Rogers J (2012) Inflammation in Alzheimer disease: a brief review of the basic science and clinical literature. Cold Spring Harb Perspect Med 2:a006346. CrossRef Medline

Yang G, Parkhurst CN, Hayes S, Gan WB (2013) Peripheral elevation of TNF-alpha leads to early synaptic abnormalities in the mouse somatosensory cortex in experimental autoimmune encephalomyelitis. Proc Natl Acad Sci U S A 110:10306-10311. CrossRef Medline 